\title{
A smart market for passenger road transport (SMPRT) congestion: an application of computational mechanism design
}

\author{
Sheri Markose ${ }^{\mathrm{a} *}$, Amadeo Alentorn ${ }^{\mathrm{b}}$, Deddy Koesrindartoto ${ }^{\mathrm{b}}$, \\ Peter Allen ${ }^{c}$, Phil Blythe ${ }^{d}$ and Sergio Grosso ${ }^{d}$ \\ ${ }^{a}$ Centre for Computational Finance and Economic Agents (CCFEA) and the Department of \\ Economics, University of Essex, U.K. \\ ${ }^{\mathrm{b}}$ Centre for Computational Finance and Economics Agents, University of Essex, U.K. \\ ${ }^{\mathrm{C}}$ Cranfield Management School, U.K. \\ ${ }^{\mathrm{d}}$ Transport Operation Research Group (TORG), Newcastle University, U.K.
}

This paper is forthcoming in the Journal of Economic Dynamics and Control, June 2007

\begin{abstract}
To control and price negative externalities in passenger road transport, we develop an innovative and integrated computational agent based economics (ACE) model to simulate a market oriented "cap" and trade system. (i) First, there is a computational assessment of a digitized road network model of the real world congestion hot spot to determine the "cap" of the system in terms of vehicle volumes at which traffic efficiency deteriorates and the environmental externalities take off exponentially. (ii) Road users submit bids with the market clearing price at the fixed "cap" supply of travel slots in a given time slice (peak hour) being determined by an electronic sealed bid uniform price Dutch auction. (iii) Cross-sectional demand data on car users who traverse the cordon area is used to model and calibrate the heterogeneous bid submission behaviour in order to construct the inverse demand function and demand elasticities. (iv) The willingness to pay approach with heterogeneous value of time is contrasted with the generalized cost approach to pricing congestion with homogenous value of travel time.
\end{abstract}

JEL Classification: R41, R48, C99, D44, H41

Keywords: Congestion charging; Negative externalities; Agent based computational auction design; "Cap” and trade smart market; Willingness to pay; Cross sectional demand analysis

*Tel.: +44 1206 872742; fax: +44 (0)1206 872724

E-mail address: scher@essex.ac.uk

Acknowledgements: We are grateful to Foresight Directorate of the UK Office of Science and Technology in the Department of Trade and Industry (DTI) for financing this project and to Miles Yarrington for project management. We also thank the Gateshead Metropolitan Borough Council for the use of their micro transport model for central Gateshead. This has been used entirely for purposes of research. We are grateful to Frank Kelly, John Urry and Andrew Scurry for their comments. Our particular thanks go to the referee, John Ledyard, for his significant technical corrections and high calibre input. We remain responsible for all errors. 


\section{Introduction}

Agent based Computational Economics (ACE) and its pragmatic arm of computational mechanism design which involves human experimental input and computational "wind tunnel testing” (see, Friedman and Sunder (1994), Roth (2002), Dash et. al. (2003), Ledyard and Szakaly-Moore (2004), Arifovic and Ledyard, this issue, Markose and Sunder (2007)) is a fast growing new subfield of economics and computer science. It has also become the norm for the design of institutions. Economic agents are effectively computer programs representing decision rules for behaviour within an artificial environment. Agents can have varying degrees of computational intelligence and autonomy to learn and adapt to their environment. Likewise, the environment can be represented in a stylized way or in terms of what has been called "model verité" viz. with the full capacity to represent real time data, Markose and Sunder (2007). Economic agent modelling is increasingly being used to "wind tunnel” test market protocols and their variants in advance of implementation. It is useful to know if the proposed design will achieve intended outcomes or bring about unintended consequences that are socially undesirable. The latter arise directly through poor design of protocols or indirectly through strategic behaviour permitted or even encouraged (inadvertently) by the protocols. Agent based models have been used to understand the properties of auction design (Andreoni and Miller (1995), Koesrindartoto (2004)) and more recently they have been used for real world design applications such as reforming of electricity markets (Bower and Bunn (2001), Bunn and Oliveira (2001), Koesrindartoto and Tesfatsion (2004)).

Traditional modelling for policy design uses econometric or analytical methods. Econometric methods run into what is known as the Lucas critique that arises from the lack of structural invariance as agents game the system (see, Markose, 2005). In other words, the estimated parameters of behavioural equations are no longer valid after the change of policy rules. Further, analytical methods use simplifying assumptions for tractability and cannot in many cases give "ball park" figures for the actual responsiveness of the system.

In this paper, to control and price negative externalities in passenger road transport, we develop an innovative ACE model to simulate a market oriented "cap" and trade system. The ACE model provides an integrated framework that can be used for most road network systems. The core of the design is a Smart Market which elicits valuations from potential road users through an on-line bid submission process with a Dutch auction protocol to determine the market clearing price and the determination of winners and losers, hence, the acronym of SMPRT which stands for Smart Market for Passenger Road Transport. The smart market concept with the use of a bid submission process that signals willingness to pay for immediacy or priority of service in the context of Internet congestion was first suggested by Mackie-Mason and Varian (1995). ${ }^{1}$ The approach based on the willingness to pay which reveals road

\footnotetext{
${ }^{1}$ McCabe et. al.(1991) discuss how smart computer-assisted markets involve online aggregation of decentralized information such as on the preferences, valuations, capacity and budget constraints of potential users or suppliers of a resource with a centralized market/auction protocol or algorithm that determines prices and allocations. The design behind a smart market is critical for it to work effectively as a coordination device and to solve resource allocation problems in specific cases with
} 
users' different valuations of travel time marks a departure from the traditional generalized cost approach to congestion externality (see, Walters (1961), Vickrey (1969)) which assumes a homogenous value for travel time.

The recent introduction in California of the dynamic and ambient congestion pricing ${ }^{3}$ of "Express" lanes of certain commuter interstate routes at peak time improves the welfare of those with higher valuations of travel time. They seek to avoid congestion on the free lanes and enhance predictability in travel time by paying the toll $^{4}$ (see, Small et. al. (2005), and Brownstone et. al., (2002)). This approach works when there are alternative non-priced roads for travel for the relevant origindestinations. ${ }^{5}$ Further, in this design of road pricing, there is no concern about maintaining overall efficient use of fixed road capacity and hence there is no analysis on whether the price charged on the Express lanes is sufficient to cover the road user externality costs in both the priced and non-priced lanes. As there is no evidence of a reduction in the number of road users on the route, this may indeed be unlikely to be the case.

The "cap” and trade approach used in our design of SMPRT is inspired by the principle of assigning property rights to the "bads" of economic activity as a means of controlling negative externalities. A landmark application of the latter arose with the Title IV of the 1990 Clean Air Act Amendments in the U.S ${ }^{6}$ which aimed at reducing sulphur dioxide $\left(\mathrm{SO}_{2}\right)$ emissions from coal and oil fired electricity generating plants (see, Schmalensee et. al. (1998), Joskow et. al. (1998)). Significant to this framework, as opposed to traditional command and control methods where a plethora of prescriptive engineering and performance standards on the abatement technology is imposed at the level of the individual polluter, is the shift of focus to the total acceptable amount of the negative factor from the economic activity at a collective level. While often as in pollution control, the "cap" is determined by some grandfathering principle, in our model of road user charging, the "cap" refers to the efficient volume of traffic which determines the fixed supply of travel slots, denoted by $\mathrm{X}^{\#}$, in a given time slice (8am-9am week-day morning peak hour) on a cordon area of a road network identified as a congestion "hotspot". This efficient volume of traffic is determined by a state of the art road traffic micro-simulator whereby the so

complex features such as, in this case, the pricing and control of negative externalities from an economic activity.

${ }^{3}$ The prices adjust typically every 6 minutes to maintain traffic at free flow levels which involves a density of less than 27 vehicles per lane per mile. The fee is posted upstream from the entrance to the lanes and road users decide 'on the spot' whether to pay to use the Express lanes or to use the nontolled lanes.

${ }^{4}$ Tolls are collected on a per trip basis electronically by a system called Fast Trak which requires users of tolled roads to subscribe.

${ }^{5}$ Sheri Markose is grateful to Frank Kelly for bringing this to her attention.

${ }^{6}$ The proposed target of sulphur dioxide $\left(\mathrm{SO}_{2}\right)$ emissions from coal and oil fired electricity generating plants was a 10 million ton per year reduction (totalling about 50\% ) from 1980 emissions levels to be achieved by the year 2000 and starting in 1995. Owners of existing affected units were given fixed numbers of tradable permits each year. These were called "allowances" and the rules governing their allocation depended primarily on historic emissions generation and fuel use. New entrants to the industry would be obliged to buy their allowances from existing units or at the Environmental Protection Agency (EPA) auctions. 
called production function of traffic with total distance travelled by all vehicles demanding service, taken as the total positive "output" of the system, begins to drop with incremental growth in vehicle volumes. This is taken as a measure of how the benefits from travel fall when many who may have successfully traversed the cordon area within a given time, can no longer do so due to the gridlock. This is also the point at which the environmental externalities from vehicular emissions were found to take off exponentially. Thus, although we adopt a "cap" and trade approach used in pollution control, it is important to note that there is a crucial difference between a fully tradable system of permits for negative externalities abatement and the bid-only market for fixed slots. In the first, all participants are given an incentive not merely to seek out cheaper alternatives but also to use revenues received from sales to make necessary abatement investments. A large part of the auction design in the case of pollution permits is geared toward achieving that objective. In the bid-only system for travel slots, the revenues are collected solely by a transport authority and the latter alone has access to funds to make the technological improvements for abatement of the externality. In keeping with the rationale of the "cap" and trade approach, it is critical that revenues collected incentivize a new wave of technological innovation for low impact transport modalities. Indeed, the prescription of the 'cap', beyond which congestion reduction is not necessary, is a useful device to prevent monopoly pricing that could follow from the bid-only framework of road user charging.

The SMPRT simulator was applied to price congestion in a real world city centre congestion 'hot spot' in central Gateshead in the U.K. Extensive data analysis was done by Peter Allen to identify the heterogeneous demand characteristics that correspond to actual income, demographic and socio-economic classes of the commuters who traverse the cordon area. Thus, the simulation of the bid submission process by road users was done in a fully disaggregated way based on this demand analysis. The results of the agent based SMPRT simulations of the heterogeneous bid submission process of actual road users have been very illuminating and yields new insights for issues regarding willingness to pay and the value of travel time. The application of a uniform price auction rather than a discriminatory one is related to the need to determine unique market clearing prices and an inverse price function. ${ }^{7}$ The heterogeneous value of time is determined by the marginal road users who respectively clear the market at different levels of biddable travel slots. This can be contrasted with the econometric panel data analyses based on reported and stated preference for value of travel time that have been used in the case of the dynamic congestion pricing in Express lanes in California (Small et. al. (2005), and Brownstone et. al. (2002)). Compared to the traditional generalized cost function models for road use, the auction based approach enables the experimenter to probe the system for demand elasticities with respect to the road user price both on an aggregate and cross sectional basis across different socio-economic classes. Indeed, as will be discussed later, in the generalized cost approach to congestion charging, the aggregate demand elasticity is not integral to the model and has to be obtained in an ad hoc way. Further, the identification of the winners and losers, in the agent based SMPRT framework, can be linked to the home-work spatial locations of the region for

\footnotetext{
${ }^{7}$ At the levels of excess demand currently present and forecasted to persist in the medium term future, our robustness analysis shows that the uniform price auction generates more revenues than the discriminatory auction (see, Markose et. al. (2006) and Koesrindartoto (2004)).

${ }^{9}$ Allen (1997, a,b) has recommended that such ACE models be used for an integrated analysis of transport and land use models.
} 
simulations on the longer term implications of road user charging and for the more efficient provision of public transport. ${ }^{9}$

A final important aspect of the empirical implementation of the SMPRT simulator is the finding that the simulator can be applied in two distinct ways. For this, it is useful to distinguish between road networks that have a high proportion of habitual car users (example, peak time week day city centre traffic) and those with a high proportion of road users that vary from one day to the next (for example, the M25 London orbital road, especially on weekends and bank holidays). In both cases, the determination of the optimal "cap" for the road network system is the benchmark. In the case of habitual road users whose home-to-workplace origin destination (OD) matrix and demand distributional characteristics is available, this data can be used to calibrate the SMPRT simulator to determine the "cap" related price for congestion and environmental externalities. However, the actual implementation of the SMPRT to operate as an opening call market to determine the market relevant price for peak time road use may be necessary only in the case of road networks where the actual users have demand distributional characteristics that are highly variable over time. Where an actual bid submission process needs to be implemented, the mechanism designer has to provide a robustness analysis of the feasibility of the auction protocol to deliver the requisite revenue from the bids. This crucially depends on whether agents will bid their true values, an assumption that is made in the simulated format of the SMPRT. Again, an ACE approach based on the Erev-Roth (1998) reinforcement learning was developed to show how, under conditions of strategic bidding, the critical level of demand pressure (relative excess demand to the "cap" supply) needed for the proposed SMPRT protocol to work in practice. However, due to space constraints, the results from these are reported elsewhere Markose et. al. (2006).

The rest of the paper is organized as follows. In Section 2, we first give a brief introduction to the rationale for pricing road use externalities and some issues raised by the London congestion charging experience. The generalized cost approach to pricing congestion externality is given in Section 2.3 followed by the auction based approach. Section 3 outlines the determination of the "cap” based on the transport micro-simulation of central Gateshead. The congestion costs in time and other traffic induced output from the transport simulations are recorded as vehicle volumes are scaled up and down from existing demand. Section 4 gives a discussion of the demand analysis and the bid submission data for road users who currently traverse the cordon area in morning peak hour of 8-9am. Section 5 gives the SMPRT inverse price function and the estimates for demand, income and speed elasticities. The SMPRT price which equals marginal social cost is found to be less than the price that clears the market at the "cap" determined by the transport simulator. The generalized cost function estimates for congestion externality cost is compared with the estimate given in the case of heterogeneous value of time. Section 6 gives concluding remarks and indicates future work needed. ${ }^{10}$

\section{Pricing of road use externalities: generalized cost approach and bid based smart market for congestion pricing}

\footnotetext{
${ }^{10}$ Note, all SMPRT inputs and outputs relating to the clearing prices and winner determination can be obtained by running the Smart Market simulator at http://www.essex.ac.uk/ccfea/research/ACE/ace_research.htm . See also the Foresight report of Markose et. al. (2006).
} 


\subsection{Why control and price negative externalities of road use?}

The traditional view is that economic development with its ever increasing demand for road transport and the consumption of non-renewable energy sources in this mode of transport, with their respective consequences of congestion and pollution, are necessary evils that must be collectively borne. A program of economic development that fully prices and internalizes the externality costs that the private cost-benefit calculus cannot incorporate, is increasingly being seen as essential to prevent the overuse and degradation of resources. The latter is powerfully brought out in Garett Hardin's classic paper on the "Tragedy of the Commons" (Hardin, 1968), where a decline in social welfare and total output occurs when there is no institution to signal and correct for the negative impact of private behaviour on society as a whole.

Congestion, pollution and other environmental negative externalities from road transport arise when the volume of traffic exceeds the free flow capacity of the road network and when any additional vehicle causes increased delays to other vehicles with a knock on effect of higher environmental costs to society as a whole. Road users incur only their private costs and not the full marginal social costs of congestion and hence over-use occurs because there is no publicly available signal when total social benefits start falling. The implementation of road pricing schemes such as toll cordons to cover such externality costs, rather than to raise revenue or to recover costs of road building and maintenance, is relatively new. ${ }^{11}$ Optimal road pricing can be viewed as the application of a corrective Pigouvian tax (Pigou, 1920) that seeks to internalize the costs of the negative externality via a marginal social cost principle. However, till recently, the negative externalities from road use were notoriously difficult to estimate, let alone cost. Marginal social cost pricing of road use externalities has been considered by many to be impractical to determine and implement and when it manifests as a spot price applying in a person-place-time specific form, it has been criticized on the grounds that road users need to know what to pay before the journey, Nash and Sansom (2001). ${ }^{12}$ Further, political constraints are cited for why the use of road pricing has failed to materialize except in a limited number of cities, despite the growth of traffic congestion. Nevertheless, the continued and predicted growth in the ownership of cars and the use of HGVs for the distribution of goods, along with environmental concerns of expanding road capacity has led to innovative traffic management and demand mitigation strategies being actively sought by governments of many countries and especially in the U.K.

\subsection{Some issues with London congestion charging}

The London congestion charging scheme which was introduced on 17 February, 2003, involved a single charge of $£ 5$ on vehicles to drive or park in the central London zone from 7am-6.30 pm. It is a major example of a successful social experiment, in addition to the ones in Singapore and Durham, in that the public has

\footnotetext{
${ }^{11}$ In the U.K., the Ministry of Transport Smeed Report of 1964 first proposed the idea of pricing roads as a function of congestion costs.

12 The ADEPT (Automatic Debiting and Electronic Payment for Transport) project, which conducted a field study in Cambridge over a period of three years from October 1992, is such an example of spot pricing (Blythe, 1993, and Blythe and Hills, 1994). By all accounts, the field study signalled the feasibility of the technology involved in monitoring and charging traffic in a radially configured cityscape with a fixed (18) number of entry points. The ADEPT scheme relied on an on-board device that was electronically activated and deactivated on entry and exit from the city limits. Once activated, the device connected to the odometer of the vehicle and would charge by debiting from a smartcard only during periods in which the speed and distance travelled signalled a state of congestion.
} 
complied with a congestion charge. The London congestion charge was recently increased to $£ 8$. However, it is far from the case that the determination of the fixed charge, the increase in it and the analysis of the economic implications of the charge along a number of relevant dimensions have been based on a set of modelling tools that can be tested out or reproduced in a coherent and integrated manner. Shaffer and Santos (2003) claim that the estimated fall in the volume of vehicles in the Central London zone after the introduction of the charge has been about $15 \%$ and that it has resulted in a $21 \%$ increase in speed, thus implying that the congestion charge of $£ 5$ is about right according to a "generalized" marginal congestion cost calculation done $e x$ post. The moot point is that the $£ 5$ charge and the increase to $£ 8$ were not based on an identifiable notion of efficiency of road use in the cordoned area and there is no target optimal volume of "passenger car units" (PCUs, for short). Note, the latter is a standardized measure for vehicles of different sizes. Hence, apart from noting that there have been improvements in congestion in London, there is no means of assessing the extent to which congestion abatement is to be pursued. ${ }^{13}$ Further, while some estimates of price elasticity of aggregate demand are made, there is little scope to gauge the price elasticities of demand for the different socio-economic and income groups of road users and hence of the impact of the charge on the less well off. Last but not least, as there has been no transparency with regard to the allocative rules governing the revenues raised, the public authorities can exploit their monopoly status by raising the congestion charge by a large margin in the face of inelastic demand.

\subsection{Homogenous opportunity cost of travel time}

Typically, all costs from road transport are found to grow inversely with the average speed of traffic, and congestion costs arise from increased journey time, $\mathrm{T}$. With volume of traffic, $X$, given in standardized passenger car units, PCU ${ }^{14}$, the average speed per hour is defined in terms of the average number of kilometres travelled, $\mathrm{AKT}(\mathrm{X})$. Then, the average journey time in hours, AT, for the unit distance of a kilometre is:

$$
\mathrm{AT}(\mathrm{X})=\frac{1}{A K T(X)}
$$

The total journey time in hours for all $\mathrm{X}$ vehicles is

$$
\mathrm{TT}(\mathrm{X})=\frac{X}{A K T(X)}
$$

The well established concept of congestion externality cost (see, Walters (1961), Vickery (1969)) follows from the fact that while the individual road user only experiences the average travel time related cost, he is unable to "internalize" the marginal impact on the total journey time of all X road users. Marginal total journey time in hours, MTT,

\footnotetext{
${ }^{13}$ Indeed, currently as reported in the Transport for London (TfL) document (2003, p.46) apart from the notion of free flow conditions of traffic, there appears to be no methodology being used to determine the optimal level of congestion. The TfL document considers that while there is an "optimal" level of congestion, it is too difficult to determine what it is.

${ }^{14}$ Note, however, we will use terms such as vehicles, commuters or road users interchangeably when referring to PCUs.
} 


$$
\operatorname{MTT}=\frac{\partial T T(X)}{\partial X}=\frac{1}{A K T(X)}\left(1+\varepsilon_{s / X}\right)
$$

Here ,

$$
\varepsilon_{s / X}=\frac{\partial A K T(X)}{\partial X} \frac{X}{A K T(X)},
$$

is the elasticity of speed to volume of traffic. ${ }^{15}$ Equation (2) implies that for every increment in traffic results in $\varepsilon_{s / X}$ times more travel time inflicted on the rest of the road users than what is experienced by the added vehicle. The congestion externality in travel time in hours, is thus:

$$
\mathrm{ET}=\mathrm{MTT}-\mathrm{AT}=\frac{\varepsilon_{s / X}}{A K T(X)} .
$$

The generalized travel cost approach used in many current calculations of congestion charging (see, Newbery (1990), Blake and Santos (2003)) assumes an average cost per vehicle journey for a unit distance of a kilometre, $C(X)$. The so called generalized cost function $\mathrm{C}(\mathrm{X})$ has two main components ${ }^{16}$ : (i) a standardized vehicle operating cost, VOC, which includes costs such as fuel, maintenance, insurance and road tax, and (ii) a homogenous value of journey time, VOT, for all commuters. Thus, the generalized travel cost function when applied to (1.a) above gives:

$$
\mathrm{C}(\mathrm{X})=\mathrm{VOC}+\frac{V O T}{A K T(X)} \text { Dist }
$$

Here, Dist is the average trip length.

With $\mathrm{X}$ volume of traffic, the social cost with $\mathrm{SC}=\mathrm{XC}(\mathrm{X})$, yields the marginal social cost for congestion externalities, MSC :

$$
\begin{aligned}
\operatorname{MSC}(\mathrm{X})=\frac{\partial S C}{\partial X} & =\mathrm{VOC}+\frac{V O T}{A K T(X)} \text { Dist }+\frac{V O T}{A K T(X)} \varepsilon_{s / x} \text { Dist. } \\
& =\mathrm{C}(\mathrm{X})+\frac{V O T}{A K T(X)} \varepsilon_{s / x} \text { Dist. }
\end{aligned}
$$

\footnotetext{
${ }^{15}$ Note the evaluation of elasticity at $\mathrm{X}$ when implemented in terms of discrete changes with $\Delta \mathrm{X}>0$ is given by: $\varepsilon_{s / X}=\frac{\Delta A K T(X)}{A K T(X)} / \frac{\Delta X}{X}=\frac{\Delta A K T(X)}{\Delta X} \frac{X}{A K T(X)}$. We follow the convention that elasticities are given in absolute terms.

${ }^{16}$ It is also possible to include a third generalized cost, viz. the environmental cost of road use. This is often included as a generalized unit cost rather than one which is a function of speed or AKT per hour. In the traffic micro-simulation, the latter was found to be the case, which implies a further environment externality cost in addition to the unit cost. Again, for reasons of space constraints, the analysis of environmental costs of road use is omitted here.
} 
Here $\varepsilon_{s / x}$ is the elasticity defined in (3). As the marginal social cost, MSC, is greater than the unit cost $\mathrm{C}(\mathrm{X})$, the congestion externality cost , $\mathrm{E}$, is what needs to be added on to the unit $\mathrm{C}(\mathrm{X})$ for road users to "internalize" it and reduce traffic. However, the evaluation of this must be done at the volume of traffic formally denoted as $\mathrm{X}^{*}$ at the social optimum where the marginal social benefit of travel equals the marginal social cost. $^{17}$ From (6), the pure congestion externality cost, E, can be formally given as:

$$
\mathrm{E}\left(\mathrm{X}^{*}\right)=\operatorname{MSC}^{\mathrm{c}}\left(\mathrm{X}^{*}\right)-\mathrm{C}\left(\mathrm{X}^{*}\right)=\frac{V O T}{A K T\left(X^{*}\right)} \varepsilon_{\mathrm{s} / \mathrm{x}} \text { Dist. }
$$

While data on vehicle operating costs can be standardized, the main drawback of the generalized cost approach is that as the opportunity cost of time, VOT, is taken to be the same for all road users, it has no bearing on how the growing congestion will affect demand for road use by commuters with different time costs. Further, within the framework, there is no means of determining the aggregate demand curve for travel associated with congestion charging at different traffic volumes $\mathrm{X}$. In other words, all manner of assumptions have to be made to estimate actual price demand elasticities (see, Walters (1961), Goodwin (1992), Oum (1999)) which is crucial even for the evaluation of (7).

\subsection{Heterogeneous opportunity cost of travel time and willingness to pay}

Commuters who traverse the cordon area belong to G different "types" or socio-economic groups with corresponding income distributions. Let $\bar{n}_{g}$ denote the total number of commuters of each type $g=1,2, \ldots \ldots G$ and $n_{\text {ig }}$ refers to the ith agent in his group with $n_{i g}=1,2 \ldots \ldots . ., \overline{n_{g}}$. Note $\mathrm{X}$ denotes the total number of commuters of all types who travel in a given hour,

$$
X=\sum_{g=1}^{G} \sum_{n_{i g}=1}^{\overline{n_{i g}}} n_{i g}
$$

Note, notation involving $\mathrm{X}, \mathrm{X}^{\#}<\mathrm{X}^{*}<\mathrm{X}^{0}$, will also refer to the rank order of commuters such as in the case of all $n_{\text {ig }}$ with the $X$ highest valuation.

As the bulk of peak time, week day demand for road use is a derived demand from work, the budget for commuting and the value of time is related to commuters' income. Denoting the pro rata daily income and hourly income of the $\mathrm{n}_{\mathrm{ig}}$ road user, respectively, as $\mathrm{y}^{\mathrm{d}}\left(\mathrm{n}_{\mathrm{ig}}\right)$ and $\mathrm{y}^{\mathrm{h}}\left(\mathrm{n}_{\mathrm{ig}}\right)$ and assuming that a fixed proportion, $\alpha$, of daily income is spent on commuting to work, the total net private budgetary benefit from the trips is given by :

\footnotetext{
${ }^{17}$ Indeed, Varian (1993, p.553) has noted that the problem with this Pigouvian tax approach is that we need to know the optimal level of the negative externality (viz., the optimal level of congestion in this case) in order to impose the tax or charge. Varian goes on to say that if we knew the optimal level of say congestion, then we could just control the level of traffic volume "and not have to mess with this taxation/charging scheme.” In effect, the SMPRT is doing precisely this, ie., we control the desired volume of traffic and determine the market clearing price and demand curve.
} 


$$
\sum_{g=1}^{G} \sum_{n_{i g}=1}^{\overline{n_{g}}}\left(\alpha y^{d}\left(n_{i g}\right)-V O C-\frac{y^{h}\left(n_{i g}\right)}{A K T(X)} \text { Dist }\right) .
$$

Thus, with VOC the same as in (5), different user types are distinguished by the size of their travel budgets, $\alpha y^{d}\left(n_{i g}\right)$, and their travel time valuation. The value of travel time, VOT, or its opportunity cost for each commuter for every unit kilometre, is given by the pro rata hourly rate, $\mathrm{y}^{\mathrm{h}}\left(\mathrm{n}_{\mathrm{ig}}\right)$. The average journey time of 1 kilometre with X volume of PCUs is, as before, given by $1 / \mathrm{AKT}(\mathrm{X})$. At the given zero price current level of demand, $\mathrm{X}^{0}$, in the cordon area with average trip length within it, Dist, (9) above must be assumed to be greater than the net budgetary benefits from any other alternative mode of transport. The price as the maximum willingness to pay for road use in the cordon area by the $n_{i g}$ agents present is determined as follows:

$\begin{array}{ll}\alpha y^{d}\left(n_{i g}\right)-V O C-\frac{y^{h}\left(n_{i g}\right)}{A K T\left(X^{0}\right)} \text { Dist }=0 & \text { :For marginal } n_{i g} \text { at } P\left(X^{0}\right)=0 . \\ \alpha y^{d}\left(n_{i g}\right)-V O C-\frac{y^{h}\left(n_{i g}\right)}{A K T\left(X^{0}\right)} \text { Dist }>0 & : \text { For intra-marginal } n_{i g}, P\left(X^{0}\right)=0 .\end{array}$

Note that equation (10) states that at zero price, $P\left(X^{0}\right)=0$, the marginal $\mathrm{X}^{0}$ th road user is one whose pro rata daily and hourly income yields zero net benefit from travel and $\alpha$ in (10) is calibrated to satisfy this. Such a calibration of $\alpha$, at the existing price of zero, can be justified to manifest the revealed preference of marginal road users whose net benefit and hence willingness to pay is zero. Thus, if (10) is negative for the given volume $\mathrm{X}^{0}$, then those $\mathrm{n}_{\mathrm{ig}}$ decide not make a trip into the cordon area. In contrast, condition (11) holds for the infra-marginal road user. Equations (10) and (11) relate to $\mathrm{n}_{\mathrm{ig}}$ agents' true monetary values for work related trips at each traffic volume $\mathrm{X}$ and this will be denoted as $\mathrm{V}(\mathrm{X})$. This yields a $\mathrm{B}(\mathrm{V}(\mathrm{X})$ ) bid schedule. Graphical presentation of the uniform-price sealed bid Dutch auction is given in Figure 1. The empirical analysis on the bid values for equations (10) and (11) and the different bid schedules at different traffic volumes will follow in Section 4 . 


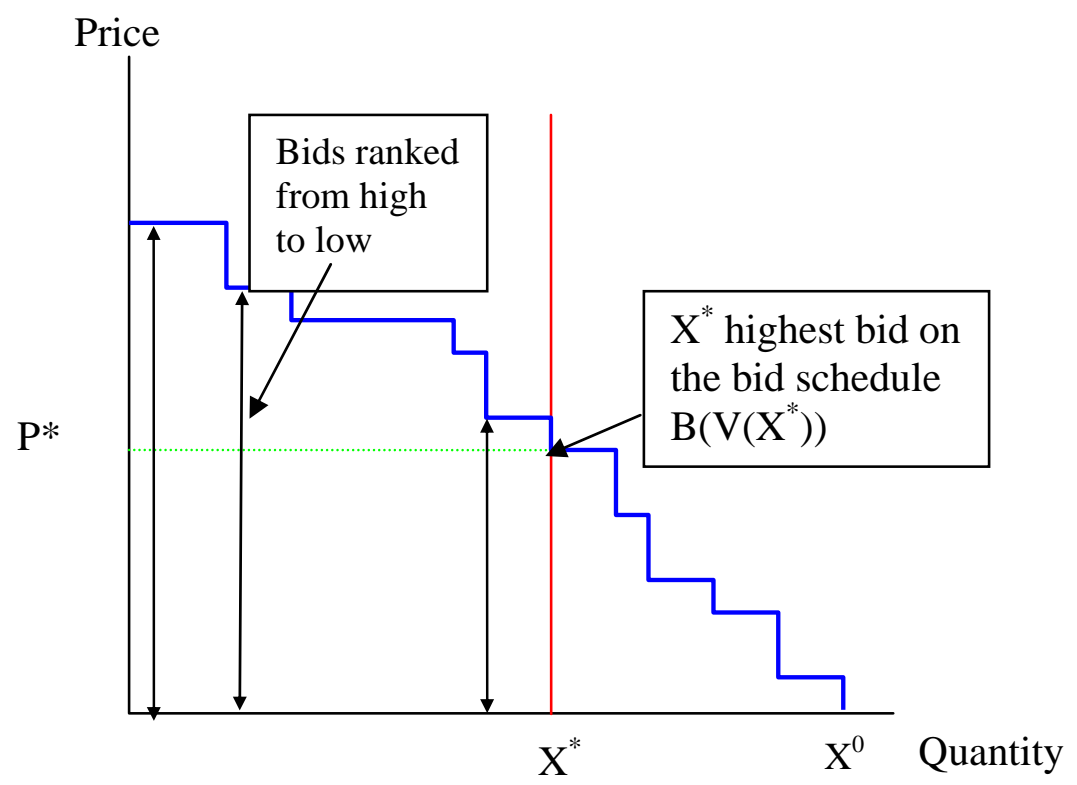

Figure 1: Price determination in uniform Dutch auction with fixed supply of $\mathrm{X}^{*}$ travel slots and actual demand of $\mathrm{X}^{0}$

When $X^{\#}$, the desired "cap" or any fixed supply of travel slots $X^{*}$ less than $X^{0}$ is imposed, with $\mathrm{X}^{\#}<\mathrm{X}^{*}<\mathrm{X}^{0}$, the sealed bid uniform Dutch auction algorithm ranks the bids of all $\mathrm{X}$ bidders from the highest to the lowest and the market clearing price, $\mathrm{P}\left(\mathrm{X}^{*}\right)$ is given by the $\mathrm{X}^{*}$-highest bid in the bid schedule $\mathrm{B}\left(\mathrm{V}\left(\mathrm{X}^{*}\right)\right)$ :

$$
\mathrm{P}^{*}=\mathrm{P}\left(\mathrm{X}^{*}\right)=\alpha y^{d}\left(X^{*}\right)-V O C-\frac{y^{h}\left(X^{*}\right)}{A K T\left(X^{*}\right)} \text { Dist }>0 .
$$

The inverse demand function in (12) directly determines $\left(\mathrm{X}^{0}-\mathrm{X}^{*}\right)$ bidders who are willing to pay less than the $\mathrm{X}^{*}$ highest bid in the bid schedule function $\mathrm{B}\left(\mathrm{V}\left(\mathrm{X}^{*}\right)\right)$. In other words, if $\mathrm{P}\left(\mathrm{X}^{*}\right)$ is charged then $\left(\mathrm{X}^{0}-\mathrm{X}^{*}\right)$ bidders will have negative net private benefit from the trip and will be priced out of the market. As will be seen, their socioeconomic cross sectional composition can also be identified. Hence, the price demand elasticity of the system can be probed for any fixed capacity, $X^{\#}<X^{*}<X^{0}$, by the operation of the uniform Dutch auction market clearing price rule.

\subsection{Market inverse demand function and congestion externality cost: heterogeneous VOT}

As heterogeneity of incomes and the implied value of time of the marginal market clearing agent at different volumes of road users, $\mathrm{X}$, is the main determinant of the equilibrium prices generated by the SMPRT Dutch auction algorithm as in equation (12), it is important to estimate the congestion charge, $\mathrm{E}$, under this assumption and compare it with the $\mathrm{P}(\mathrm{X})$ function. In the case of heterogeneous VOT, the private cost function is given as:

$$
\mathrm{C}\left(\mathrm{X}, \mathrm{y}^{\mathrm{h}}(\mathrm{X})\right)=\mathrm{VOC}+\frac{y^{h}(X)}{A K T(X)} \text { Dist. }
$$

The social cost function, $\mathrm{SC}(\mathrm{X})$, integrates the impact of the marginal driver on all infra-marginal drivers with the highest valuation drivers starting at $\mathrm{X}=0$ up to the marginal driver, $\mathrm{X}$. Thus, 


$$
\mathrm{SC}(\mathrm{X})=\int_{0}^{X} C\left(X, y^{h}(s)\right) d s=\mathrm{XVOC}+\frac{D i s t}{A K T(X)} \int_{0}^{X} y^{h}(s) d s
$$

This implies the marginal social cost, $\mathrm{MSC}(\mathrm{X})$ of travel which includes congestion externalities in the heterogeneous value of time case is given by :

$$
\begin{aligned}
\operatorname{MSC}(X)= & \frac{\partial \int_{0}^{X} C\left(X, y^{h}(s) d s\right)}{\partial X}=C\left(X, y^{h}(X)+\frac{y^{h}}{A K T(X)} \varepsilon_{s / X}\right. \text { Dist } \\
& =\mathrm{C}\left(\mathrm{X}, \mathrm{y}^{\mathrm{h}}(\mathrm{X})\right)+\mathrm{E}(\mathrm{X})
\end{aligned}
$$

Here, $C\left(X, y^{h}(X)\right)$ is given in (13) and

$$
\bar{y}^{h}=\frac{\int_{0}^{X} y^{h}(s) d s}{X} \quad \text { and } \quad \overline{\operatorname{VOT}}(X)=\frac{\overline{y^{h}}}{A K T(X)} \text { Dist }
$$

are, respectively, the average pro rata hourly annual income of infra-marginal road users and $\overline{V O T}(X)$ is the average value of time of the infra-marginal road users for the average journey length.

With the SMPRT determined inverse demand function where the price at any $\mathrm{X}, \quad \mathrm{X}^{\#}<\mathrm{X}<\mathrm{X}^{0}$ is set to reduce demand to that point, it can be easily shown that only for the social optimum, $X^{*}$, will the congestion externality cost $E\left(X^{*}\right)$ equal the price $\mathrm{P}\left(\mathrm{X}^{*}\right)$. The social optimum, $\mathrm{X}^{*}$, is obtained when the marginal social cost, MSC, equals the marginal social gross benefit, MGB, from the trip. ${ }^{18}$ This yields:

$$
\operatorname{MGB}\left(X^{*}\right)=\alpha y^{d}\left(X^{*}\right)=C\left(X^{*}, y^{h}\left(X^{*}\right)\right)+E\left(X^{*}\right)=\operatorname{MSC}\left(X^{*}\right) .
$$

This implies that at $\mathrm{X}^{*}$,

$$
P\left(X^{*}\right)=\left(\alpha y^{d}\left(X^{*}\right)-C\left(X^{*}, y^{h}\left(X^{*}\right)\right)=E\left(X^{*}\right) .\right.
$$

As the private net benefit of the marginal road user, $\left(\alpha \mathrm{y}^{\mathrm{d}}(\mathrm{X})-\mathrm{C}\left(\mathrm{X}, \mathrm{y}^{\mathrm{h}}(\mathrm{X})\right)\right.$ is equal to the price, $\mathrm{P}(\mathrm{X})$, what the willingness to pay approach indicates is that, to choke off demand and to accomplish demand consistent with any fixed "cap” X, $\mathrm{P}(\mathrm{X})$ determined by the SMPRT simulator, has to be levied. The advantage of this is that the SMPRT price can be applied to achieve any desired fixed "cap", such as $\mathrm{X}^{\#}$ selected in the next section as one beyond which a reduction in congestion may not be required on the grounds of traffic efficiency. In contrast, the congestion externality charge, $\mathrm{E}(\mathrm{X})$, is valid only at the social optimal $\mathrm{X}^{*}$. As identifying the social optimum $\mathrm{X}^{*}$ is problematic, at other values of $\mathrm{X}, \mathrm{X}>\mathrm{X}^{*}$, charging the difference between the private cost and the social marginal cost will contract demand far more than is needed. It is also clear that willingness to pay determined by the inverse demand function $\mathrm{P}(\mathrm{X})$ is less than the congestion externality cost for $\mathrm{X}>\mathrm{X}^{*}$. Figure

${ }^{18}$ Social gross benefit is $\alpha \int_{0}^{X} y^{d}(s) d s$ or the gross daily income of all the infra marginal commuters. 
2 illustrates these points and it has been calibrated in terms of the actual data obtained from the SMPRT simulations done for central Gateshead. First note that at zero price $\mathrm{P}\left(\mathrm{X}^{0}\right)=0$, the gross benefit or the travel budget of the $\mathrm{X}^{0}$ marginal commuter, $\alpha \mathrm{y}^{\mathrm{d}}\left(\mathrm{X}^{0}\right)$, is exactly equal to the private unit cost $\mathrm{C}\left(\mathrm{X}^{0}, \mathrm{y}^{\mathrm{h}}\left(\mathrm{X}^{0}\right)\right)$. The social optimum $\mathrm{X}^{*}$ in Figure 2 is obtained at PCU volume, $\mathrm{X}^{*}=12136$ where the marginal social cost curve intersects with the marginal gross benefit curve. Here, the price $P\left(X^{*}\right)=E\left(X^{*}\right)$. If the chosen cap is $X^{\#}$ with $X^{\#}<X^{*}$, the price $P\left(X^{\#}\right)$ exceeds the pure congestion cost, $\mathrm{E}\left(\mathrm{X}^{\#}\right)$ related to MSC at $\mathrm{X}^{\#}$, and there is some margin to include environmental costs of road use.

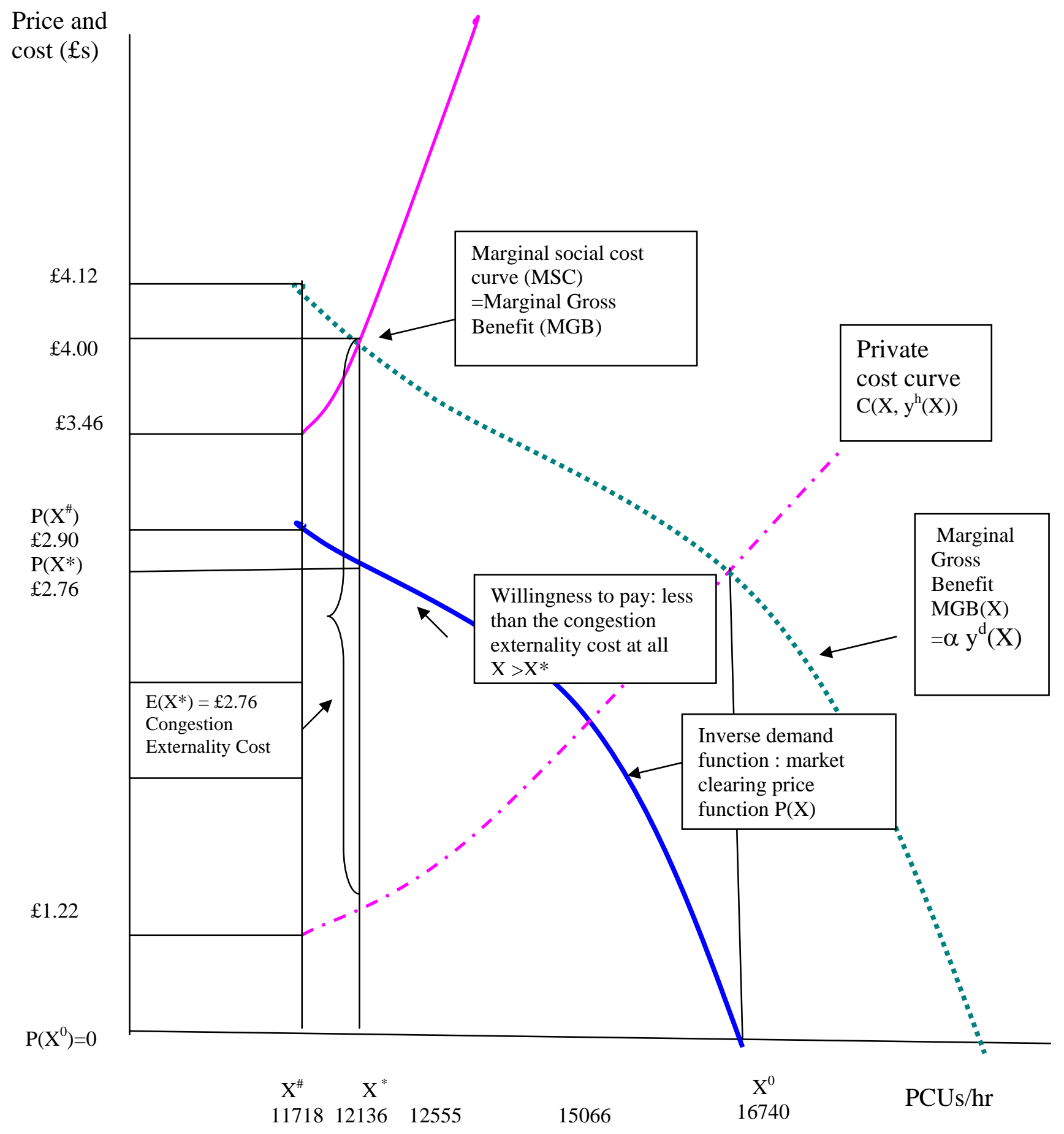

Figure 2: Integration of willingness to pay and inverse demand function $\mathrm{P}(\mathrm{X})$ with congestion externality costs $\mathrm{E}(\mathrm{X})$ at social optimum, $\mathrm{X}^{*}$ 


\section{How to determine the "cap” for the road network system}

\subsection{The traffic micro simulation of congestion}

Though the situation of free flow at permissible/legal speeds per hour is often used as a bench mark to measure the state of congestion, it is well known that zero congestion $^{20}$ is neither socially optimal nor one that coincides with efficient traffic conditions. However, to date, there has not been a consensus methodology on how to gauge the efficiency of traffic in a road network system. As explained in the introduction, in the "cap" and trade approach to the control of negative externalities of passenger car use, it is important to be able to set the "cap" in terms of the total biddable travel slots that entitle commuters to travel at a minimum average kilometres per hour in a given time slice. Here, we explain how the "cap" can be determined by an identifiable optimal level of congestion evaluated in terms of physical traffic conditions in the relevant cordoned area of road network. For this, following the philosophy of model vérité (Markose and Sunder, 2006), which is well understood in the application of traffic micro-simulators, the virtual or digitized physical environment of the cordon area of road network system of the cityscape is designed to include all relevant features such as traffic lights, topography and extant speed rules. A powerful state of the art transport micro simulator implemented by TORG derives the so called production function for traffic where total distance travelled by cars entering the cordon (the total "output") is recorded when there is incremental growth in vehicle volumes, given in standardized units of passenger car units. The increments in PCU volumes are achieved by the "scaling" of demand from baseline demand given by the existing OD (Origin-Destination) matrix of the peak time (8am$9 \mathrm{am}$ ) road users in the cordon area. The validation of traffic flow for extant traffic volumes for morning peak time traffic is achieved by using a combination of dynamic and static route assignment algorithm. The "cap" for the road network system is identified as the point at which the total output of the system measured in total distance travelled falls as volume of vehicles increase. This is accompanied with an increase in total travel time for all the vehicles.

The method of "factoring" or scaling corresponds to the notion of probing the "production technology" of traffic when increasing vehicle demand is combined with a fixed supply of road network of the cordon area. In economic analysis, this is a well understood concept for determining the point at which there are decreasing returns to scale from a factor of production. Such an analysis is critical for identifying optimal traffic conditions. Thus, relative to the baseline demand taken as factor 1 , traffic volumes that demand entry in the time slice are scaled up or down at the rate of $10 \%$ from the baseline demand, 16,740 PCU, and factors from .1 to about 1.7 are simulated for their traffic induced outputs for the cordon area. ${ }^{21}$ Table 1 and Figure 3 below

\footnotetext{
${ }^{20}$ Free flow speed with zero congestion in practice implies a congestion externality cost in time of under a minute.

${ }^{21}$ This is a computationally intensive method with execution times for factor 1.7 (ie, $70 \%$ more demand than existing demand) taking over 40 hours.
} 
give the results for the traffic induced outputs which include average kilometres travelled (AKT/PCU per hour), total travel time, total distance travelled and the travel time congestion externality estimated in minutes.

\subsection{Traffic induced output and the optimal level of congestion}

We omit here all details of the traffic micro-simulation that was done for the congestion "hotspot" in the city of Gateshead in the north of England ${ }^{22}$ and report only the main results of the analysis. As seen from Table 1 and Figure 3 , factor 1 in the peak hour traffic period of 8-9am (marked by a shaded band), some 16,700 PCUs pass through the congestion hotspot in Gateshead slowing traffic down to about $4 \mathrm{kmh}$ with the cost in minutes of the congestion externality (column 7 in Table 1) rising to about 56 minutes. Any further increases in traffic can tip the system into complete gridlock where a one kilometre journey adds a burden of 1.5 hours in terms of time cost of congestion externality. Note, the average trip length in the cordon area is $1.8 \mathrm{kms}$.

Table 1

Average speed (AKT), total journey time per kilometre, total distance travelled per hour, for different levels of demand. (Current level of demand is highlighted.)

\begin{tabular}{|c|c|c|c|c|c|c|c|c|}
\hline $\begin{array}{c}\text { Demand } \\
\text { (factor) } \\
\text { X }\end{array}$ & $\begin{array}{l}\text { Average speed, } \\
\text { average } \mathrm{km} \\
\text { travelled/hr } \\
(\text { AKT/hr) } \\
\text { (smoothed }^{23} \text { ) }\end{array}$ & $\begin{array}{l}\text { Average } \\
\text { journey } \\
\text { time for } 1 \\
\text { km trip } \\
1 / \text { AKT }\end{array}$ & $\begin{array}{c}\text { Total } \\
\text { journey time } \\
\text { (smoothed) }\end{array}$ & $\begin{array}{l}\text { Total } \\
\text { distance } \\
\text { travelled } \\
\text { by all } \\
\text { PCUs } \\
\text { per hour }\end{array}$ & $\begin{array}{c}\text { Elasticity } \\
\text { Eq(3) } \\
\varepsilon_{S / X}= \\
\frac{\Delta A K T}{\Delta P C U} \times \frac{P C U}{A K T}\end{array}$ & $\begin{array}{l}\text { ET in } \\
\text { hours } \\
\text { Eq. (4) } \\
{\frac{\varepsilon_{S / X}}{A K T}}^{24}\end{array}$ & $\begin{array}{c}\mathrm{ET} \text { in } \\
\text { minutes }^{25}\end{array}$ & $\begin{array}{c}\text { Marginal } \\
\text { total } \\
\text { travel } \\
\text { time } \\
\text { cost }^{26}\end{array}$ \\
\hline 1 & 2 & 3 & 4 & 5 & 6 & 7 & 8 & 9 \\
\hline$[\mathrm{PCU}]$ & {$[\mathrm{km} / \mathrm{h}]$} & {$[\mathrm{h} / \mathrm{km}]$} & [h] & {$[\mathrm{km}]$} & & [h] & [mins] & [mins] \\
\hline $\begin{array}{l}1674 \\
(0.1)\end{array}$ & 33.67 & 0.030 & 133.7 & 4501.1 & -0.05 & -0.002 & -0.12 & - \\
\hline $\begin{array}{l}3348 \\
(0.2)\end{array}$ & 35.38 & 0.028 & 243.3 & 8607.5 & -0.01 & 0.000 & 0 & 0 \\
\hline $\begin{array}{l}5022 \\
(0.3)\end{array}$ & 35.55 & 0.028 & 346.80 & 12329.0 & 0.12 & 0.003 & 0.18 & 1.8 \\
\hline $\begin{array}{l}6696 \\
(0.4)\end{array}$ & 34.17 & 0.029 & 492.6 & 16834.5 & 0.34 & 0.010 & 0.6 & 2.34 \\
\hline $\begin{array}{l}8370 \\
(0.5)\end{array}$ & 31.23 & 0.032 & 671.7 & 20976.7 & 1.17 & 0.038 & 2.28 & 4.2 \\
\hline 10044 & 23.91 & 0.042 & 956.3 & 22865.3 & 1.27 & 0.053 & 3.18 & 5.7 \\
\hline
\end{tabular}

${ }^{22}$ Full details of the TORG analysis can be obtained from the authors.

${ }^{23}$ The traffic induced outputs from the TORG simulation for each of the demand factors should in principle be the average of a number of trial runs. This is because due to the stochastic nature of route assignment simulations, while a single set of simulations have produced clear trends, there are some fluctuations around this. However, given the computational intensive nature of completing a single set of runs for demand factors .1 to 1.7, we have had to "smooth" the data points in some cases to follow the trend rather than average across several runs.

${ }^{24} \mathrm{ET}$ or time congestion externality cost in hours $\frac{\varepsilon_{S / X}}{A K T}$ in column 7 is obtained by multiplying column 3 figures with those in column 6 .

${ }^{25}$ This is obtained by multiplying figures in column 7 by 60 to get the time congestion externality cost in minutes.

${ }^{26}$ Marginal total travel time cost in column 9 of Table 1 and in Figure 3 is given in minutes and is obtained by adding 60/AKT to time congestion externality cost in minutes reported in column 8 of Table 1. 


\begin{tabular}{|c|c|c|c|c|c|c|c|c|}
\hline$(0.6)$ & & & & & & & & \\
\hline $\begin{array}{c}11718 \\
(0.7)\end{array}$ & 18.85 & 0.053 & 1502.5 & 28324.4 & 1.80 & 0.096 & 5.76 & 8.94 \\
\hline $\begin{array}{c}13392 \\
(0.8)\end{array}$ & 13.99 & 0.071 & 2005 & 28049.9 & 2.99 & 0.214 & 12.84 & 17.1 \\
\hline $\begin{array}{c}15066 \\
(0.9)\end{array}$ & 8.76 & 0.114 & 3091.43 & 27080.9 & 4.78 & 0.545 & 32.7 & 39.54 \\
\hline $\begin{array}{c}16740 \\
\text { (1) }\end{array}$ & 4.11 & 0.243 & 6265.0 & 26112.6 & 3.87 & 0.941 & 56.46 & 71.04 \\
\hline $\begin{array}{c}18414 \\
(1.1)\end{array}$ & 2.51 & 0.398 & 8081.27 & 20284.0 & 3.89 & 1.55 & 92.89 & 116.77 \\
\hline $\begin{array}{c}20088 \\
(1.2)\end{array}$ & 1.97 & 0.495 & 9727.8 & 19234.0 & 3.80 & 1.72 & 103.41 & 133.11 \\
\hline $\begin{array}{c}21762 \\
(1.3)\end{array}$ & 1.40 & 0.71 & 11074.9 & 15530.2 & 2.29 & 1.63 & 97.63 & 140.23 \\
\hline $\begin{array}{c}23436 \\
(1.4)\end{array}$ & 1.15 & 0.495 & 13209.42 & 15229.9 & - & - & & \\
\hline
\end{tabular}

Our analysis shows that free flow of traffic at the average speed of about 35 $\mathrm{km} / \mathrm{hr}$ corresponds to zero or under 1 minute (see, Table 1 column 8 ) of time congestion externality costs and is not optimal in terms of the production function for traffic. There are 'productivity' gains from increasing traffic beyond free flow. Indeed, the target of free flow for all vehicles for all times and all roads corresponds to a costly over provision of road space. The decline in total output in terms of total distance travelled by all cars which demand entry happens after the precipitous decline of the AKT curve (see Figure 3 ) and well beyond speeds associated with free flow. Thus, it is it is only at about factor .7 with PCU volume of 11,718 that the total output of the traffic system given in terms of total distance travelled by all PCUs starts to decline. At this point, benefits from using the cordon area falls as nobody by his/her travel can benefit without making everybody else worse off. Indeed, many who could have made it to work on time within the hour, before demand increased to more than 11,718, are now unable to do so due to the gridlock.

Marginal total journey time cost in Figure 3, given in minutes, is obtained by adding average time of the journey in minutes, viz.60/AKT, with the time cost of congestion externality in minutes reported in column 8 of Table 1 . Thus, in the case of factor 1 demand of 16740 PCUs, the marginal total cost of a kilometre trip is given by adding 14.59 minutes to 56.46 minutes, which gives about 71 minutes (see column 9 in Table 1). Further, along all the critical aspects of negative externalities from road transport, it was found that at this point, at factor 0.7 with PCU volume of 11,718 , the growth of total travel time and that of vehicular emissions altered from being linear to an exponential rate. Thus, we conclude that for the cordon area for central Gateshead, a "cap" of about 11,718 PCUs can be recommended. This effectively requires a 30\% reduction in demand. 


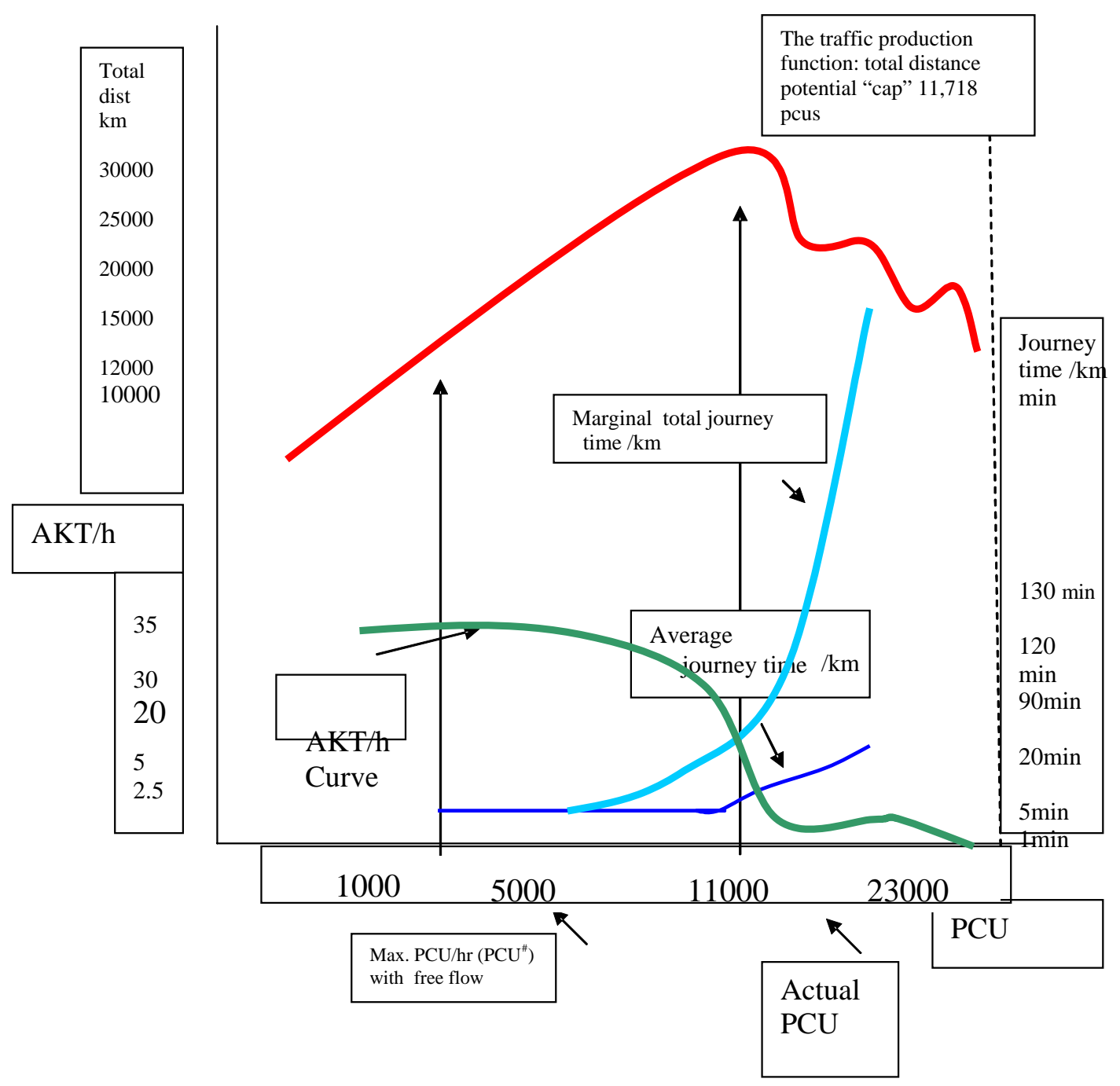

Figure 3: Congestion Externalities in Distance/hour and Journey Time/km The production function for traffic (total distance traveled in $\mathrm{km} / \mathrm{h}$ by all PCUs) AKT/hr-curve for average speed

Marginal total journey time minus average journey time = congestion externality in travel time

\section{The bid submission process and smart market (SMPRT) algorithm}

\subsection{Empirical analysis of the bid submission process}

In order to understand how road users will bid for slots to travel in a given time slice, and also to establish the efficacy of the SMPRT algorithm as a means of determining the road user charge to achieve the desired level of congestion at the "cap" for the cordon area, an extensive analysis of the socio-economic and income distribution characteristics of the commuters who traverse the cordon area of Gateshead was done. 
This is because, as discussed earlier, equations (10) and (11) which determine whether road users travel or not through the cordon area during morning peak hour and their maximum willingness to pay is based on their pro rata daily and hourly income. Note, the value of travel time VOT is imputed from the willingness to pay function of the marginal commuter whose bid clears the market for a given fixed supply of travel slots.

Table 2

Percentage of commuters in each socio-economic group

\begin{tabular}{|l|c|}
\hline Managers & $16 \%$ \\
\hline Professionals & $11 \%$ \\
\hline Semi-routine & $31 \%$ \\
\hline Administrative & $14 \%$ \\
\hline Personal service & $3 \%$ \\
\hline Sales & $14 \%$ \\
\hline Foutine & $11 \%$ \\
\hline
\end{tabular}

The range of incomes in each of these groups yields Table 3.

On superimposing the origin-destination statistics for the region with those for the cordon area, we are able to cross-correlate the peak time road users who traverse the cordoned area with the socio-economic classes of commuters in the region given in Table 2.

Table 3

Income range of each socio-economic group in the north of England

\begin{tabular}{|l|c|c|c|c|c|c|c|c|c|c|}
\hline Managers & $£ 12,983$ & $£ 17,033$ & $£ 19,898$ & $£ 23,492$ & $£ 26,711$ & $£ 29,931$ & $£ 34,092$ & $£ 40,000$ & $£ 47,719$ & $£ 53,021$ \\
\hline Professionals & $£ 9,223$ & $£ 13,759$ & $£ 17,251$ & $£ 19,567$ & $£ 21,930$ & $£ 24,294$ & $£ 26,686$ & $£ 28,477$ & $£ 33,978$ & $£ 37,753$ \\
\hline Semi-routine & $£ 10,142$ & $£ 12,310$ & $£ 14,210$ & $£ 16,152$ & $£ 17,922$ & $£ 19,692$ & $£ 21,664$ & $£ 25,021$ & $£ 30,704$ & $£ 34,115$ \\
\hline Administrative & $£ 6,216$ & $£ 8,570$ & $£ 10,833$ & $£ 12,268$ & $£ 13,461$ & $£ 14,655$ & $£ 16,114$ & $£ 18,125$ & $£ 23,557$ & $£ 26,174$ \\
\hline Personal service & $£ 4,194$ & $£ 6,117$ & $£ 7,618$ & $£ 8,870$ & $£ 10,263$ & $£ 11,657$ & $£ 13,048$ & $£ 14,345$ & $£ 17,256$ & $£ 19,173$ \\
\hline Sales & $£ 3,754$ & $£ 4,980$ & $£ 5,860$ & $£ 7,003$ & $£ 8,595$ & $£ 10,187$ & $£ 11,989$ & $£ 13,597$ & $£ 16,629$ & $£ 18,476$ \\
\hline Routine & $£ 2,022$ & $£ 3,246$ & $£ 4,831$ & $£ 6,860$ & $£ 8,999$ & $£ 11,138$ & $£ 12,980$ & $£ 15,505$ & $£ 19,381$ & $£ 21,534$ \\
\hline
\end{tabular}

Based on the multi-modal study of commuters in the region (Ove Arup Report, 2002), we know that $78 \%$ of commuters are car drivers, and that the distribution of drivers is skewed towards the high earners. We do not have car 
ownership data for the socio-economic classes. Therefore, we choose a threshold under which we assume an individual could not afford to drive a car. A threshold of $£ 10,500$ when applied to the disaggregated income data in Table 3 gave us the required outcome that $78 \%$ of commuters are car drivers. Further, on assuming the total population of car users to be 16,740 , we obtain the income distribution given in Figure 4.

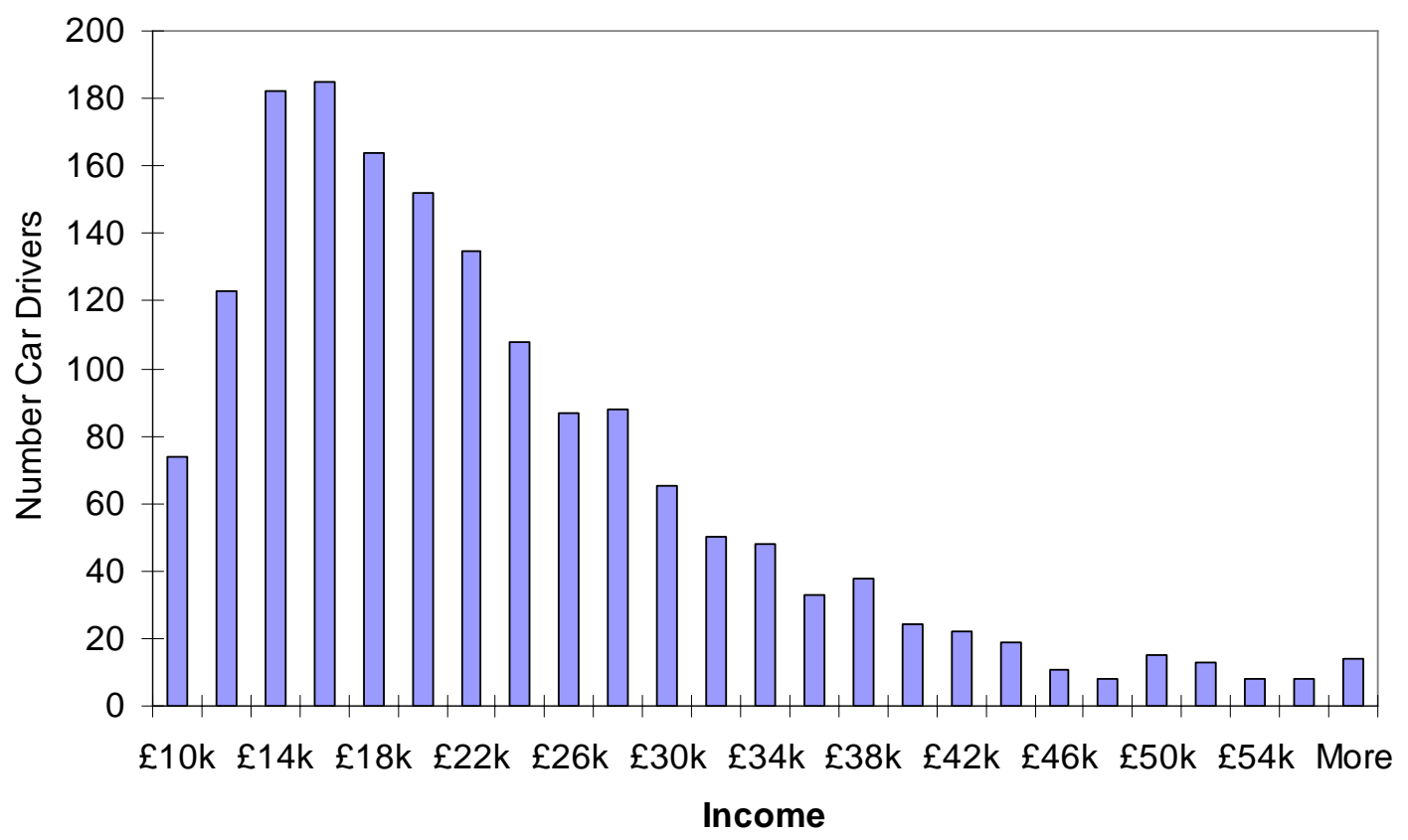

Figure 4: Income distribution of car drivers (mean annual income is $£ 21,990.39$ )

\subsection{Empirical bid schedules of different socio-economic groups of road users}

Using the income data for each of the 16740 road users and with the standardized Vehicle Operating Costs (VOC) calculated to be 47.48 pence ${ }^{27}$ for the cordon average trip length of $1.8 \mathrm{kms}$, equations (10) and (11) in Section 2.4 were used to determine their bids. Further, the data on AKT/hr for the PCU volume from Table 1 is used. Note, also $\alpha$, the proportion of pro rata daily income which determines the travel budget, is determined to be .066 by calibrating equation (10) so that the market clearing bid at current demand of 16,740 equals zero. The following Table 4 gives the bid schedules for the average agent in each of the professional categories where a bid has to be made for a travel slot to travel at a speed given in top row of Table 4.

The bid schedules given in Table 4 are plotted in Figure 5 with a colour code for each group. With AKT/hr on the vertical axis and $£$ value of bids on the horizontal axis, the representative agent from the higher income group has a bid schedule further to the left (viz. higher $£$ value) than those in lower income groups. Note from equations (10) and (11) in traffic conditions of close to free flow speeds, size of bids is primarily determined by the size of commuters' daily travel budget, $\alpha \mathrm{y}^{\mathrm{d}}$, as the time cost of congestion 1/AKT is small.

\footnotetext{
${ }^{27}$ This based on recent figures given in Shaffer and Santos (2005).
} 
Table 4

Bid schedules at different volume of PCUs for the average/representative agent in each group *( Pro Rata daily average income is given in brackets)

\begin{tabular}{|l|l|l|l|l|}
\hline AKT/hr & 18.85 & 13.95 & 8.76 & 4.11 \\
\hline PCU/hr & 11718 & 13392 & 15066 & 16740 \\
\hline $\begin{array}{l}\text { Managers } \\
(£ 115.48)^{\star} \\
\text { Bid }\end{array}$ & $£ 3.77$ & $£ 3.44$ & $£ 2.67$ & $£ 0.35$ \\
\hline $\begin{array}{l}\text { Professionals } \\
(£ 99.41)^{\star} \\
\text { Bid }\end{array}$ & $£ 2.97$ & $£ 2.71$ & $£ 2.08$ & $£ 0.19$ \\
\hline $\begin{array}{l}\text { Semi-routine } \\
(£ 85)^{\star} \\
\text { Bid }\end{array}$ & $£ 2.44$ & $£ 2.22$ & $£ 1.69$ & $£ 0.09$ \\
\hline $\begin{array}{l}\text { Administrative } \\
(£ 67.90)^{*} \\
\text { Bid }\end{array}$ & $£ 1.86$ & $£ 1.68$ & $£ 1.25$ & $£ 0.00$ \\
\hline $\begin{array}{l}\text { Personal service } \\
(£ 60.50)^{*} \\
\text { Bid }\end{array}$ & $£ 1.59$ & $£ 1.43$ & $£ 1.06$ & $£ 0.00$ \\
\hline $\begin{array}{l}\text { Sales } \\
(£ 61.14)^{*} \\
\text { Bid }\end{array}$ & $£ 1.65$ & $£ 1.48$ & $£ 1.10$ & $£ 0.00$ \\
\hline $\begin{array}{l}\text { Routine } \\
(£ 99.41)^{*} \\
\text { Bid }\end{array}$ & $£ 1.75$ & $£ 1.58$ & $£ 1.17$ & $£ 0.00$ \\
\hline
\end{tabular}

For the higher income group (managers) with greater opportunity cost of time, the willingness to pay at higher speeds is relatively greater than at lower speeds. For example, the average range of bids for the managerial group goes from close to $£ 4$ to as little as 35 pence.

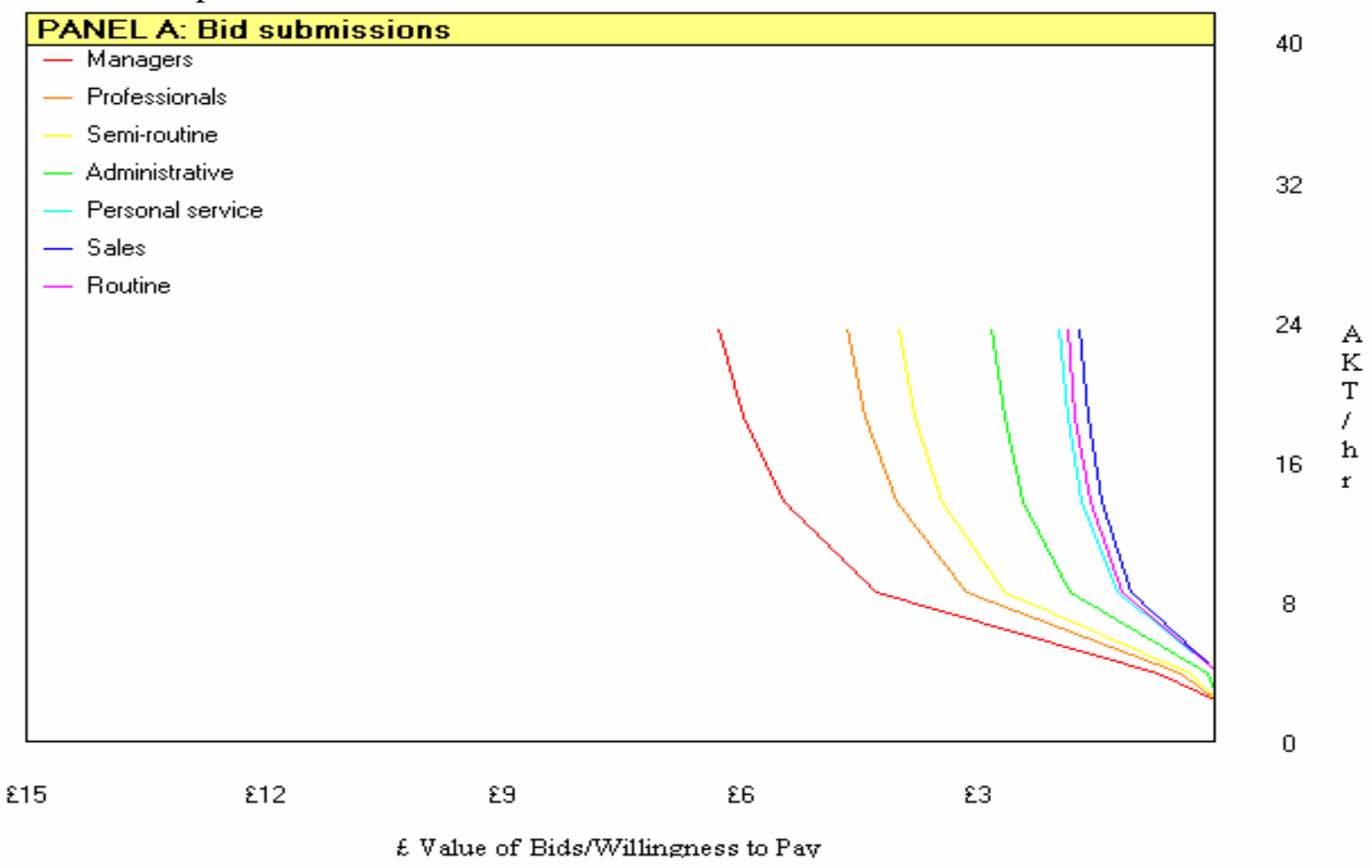

Figure 5: Bid Schedule of representative agent from each socio-economic class 
In contrast, those whose value of time is low (lower income groups) the bids remain more constant (viz., vertical in Figure 5) starting at relatively low values of about $£ 1.56$ for those in personal services, for example. This is because their VOT with pro rata hourly wage, being relatively small, they are less responsive to increasing time costs of congestion, Table 5.

Table 5

Sensitivities for bid values to change in journey time for representative agent in each group (sensitivity calculated as $(\Delta \mathrm{Bid} / \Delta(1 / \mathrm{AKT}))$

\begin{tabular}{|l|l|l|l|l|}
\hline PCU & 11718 & 13392 & 15066 & 16740 \\
\hline Managers & 5.0 & 2.7 & 0.8 & 0.1 \\
\hline Professionals & 4.9 & 2.7 & 0.7 & 0.1 \\
\hline Semi-routine & 4.9 & 2.7 & 0.7 & 0.1 \\
\hline Administrative & 4.7 & 2.6 & 0.7 & 0.0 \\
\hline Personal service & 4.6 & 2.5 & 0.6 & 0.0 \\
\hline Sales & 4.5 & 2.4 & 0.6 & 0.0 \\
\hline Routine & 4.5 & 2.5 & 0.6 & 0.0 \\
\hline
\end{tabular}

\section{Description of SMPRT simulator and results}

\subsection{SMPRT simulator inputs: AKT-curve and bid submission}

The workings of the SMPRT simulator is displayed in a 4-quadrant plot referred to as Panel A, Panel B, Panel C and Panel D. Panels A and B contain the two main inputs to the Dutch auction pricing algorithm while Panels $C$ and $D$ give the main results. Panel B displays the so called AKT-curve obtained from the TORG traffic simulator for the cordon area which gives the relationship between the speed and the volume of PCU. Below, the cursor is set at the AKT/hr of $18.85 \mathrm{~km} / \mathrm{h}$ at the “cap” for the system identified earlier in Section 3.2 at 11,718.

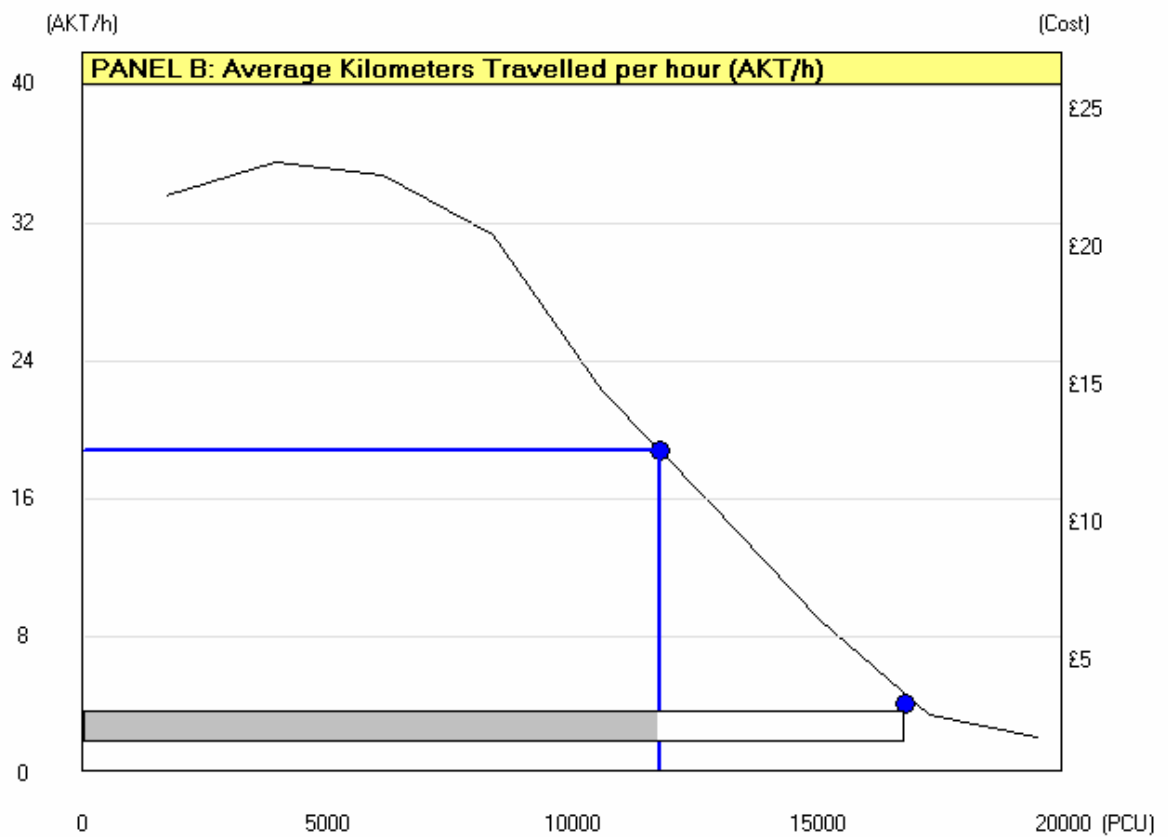

Figure 6: AKT/hr function with the cursor at cap of 11,718 PCU yield an average speed (AKT/hr) of $18.85 \mathrm{Km} / \mathrm{h}$ ). 
Panel A of the SMPRT simulator, in Figure 7 below, gives all 16,740 bid schedules as a function of AKT/hr given on the vertical axis. Note that the bids are colour coded to indicate the professional group of the bidder. (Typically, a horizontal blue line cursor in Panel A marks the cross section of bids for the AKT/hr at the chosen level of PCU.) At close to free flow AKT/hr of $24 \mathrm{~km} / \mathrm{h}$, bids start at about $£ 13$ while at the current road use demand, by construction bids are zero. Figure 7 shows that at about $8 \mathrm{~km} / \mathrm{h}$, as the system gets into a state of gridlock, bids from across the board begin to converge to zero.

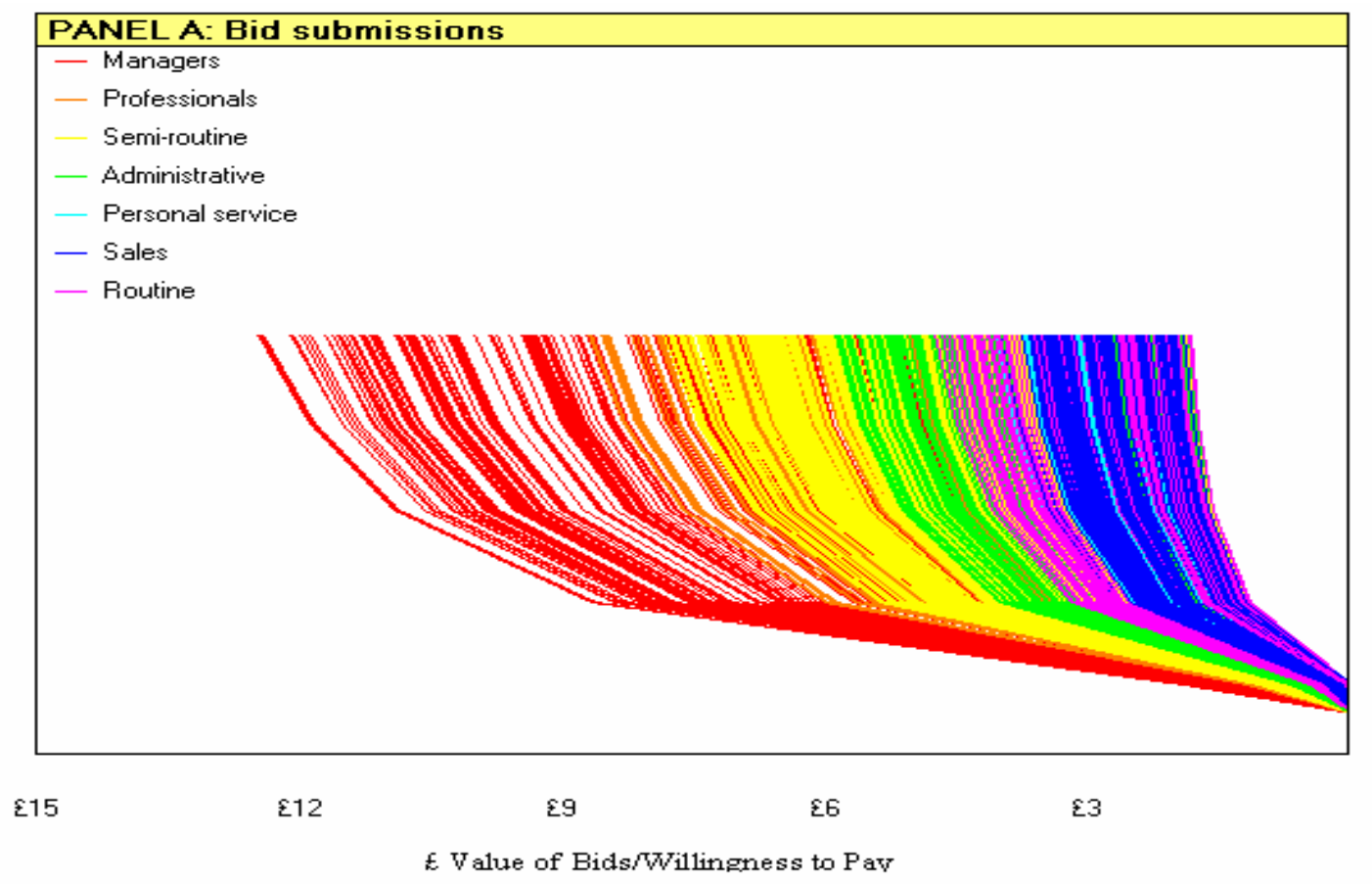

Figure 7: All 16,740 bid schedules with of AKT/hr given on the vertical axis.

\subsection{SMPRT simulation outputs: market price and market demand curve}

As explained in Figure 1 in Section 2.4, the SMPRT Dutch auction protocol ranks bids from highest to lowest, to obtain the market demand/aggregate bid schedule for a particular AKT/hr associated with the PCU level. This is plotted in Panel C of the SMPRT Simulator and shown in Figure 8. What is important to note is that if all agents have a constant bid schedule for all speeds with relevant PCU volumes (such is the case when agents bid a constant proportion of their daily pro rata income and set their sensitivity to travel time costs from congestion to zero, see Appendix 1)) then the market demand/aggregate bid schedule is the same for all levels of PCU. However, using the willingness to pay function in equations (10) and (11), there is a different market demand/aggregate bid curve for each PCU volume with its corresponding AKT/hr. In Figure 8, we show four market demand/aggregate bid schedules, one for each PCU level. The top curve corresponds to the $\mathrm{X}^{\#}$ cap of $11,718 \mathrm{PCU}^{28}$, while the lowest curve corresponds to the demand/aggregate bid function at current levels of traffic, i.e., PCU of 16,740. Note, how the clearing price at current market demand is zero.

\footnotetext{
${ }^{28}$ The SMPRT algorithm rounds off the optimal $X^{\#}$ 'cap' value to be 11,720 rather than 11,718 .
} 


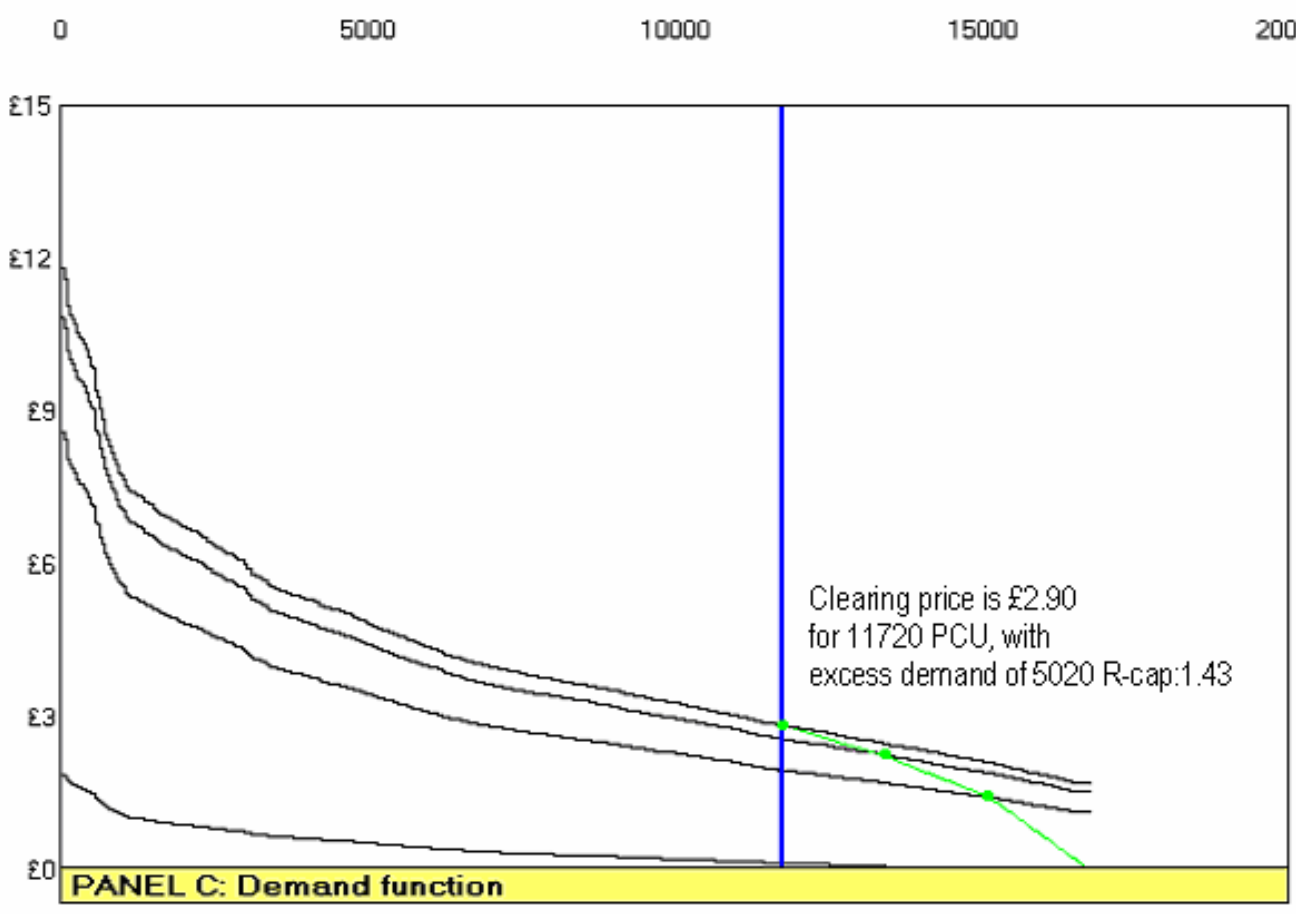

Figure 8: Inverse demand function $\mathrm{P}(\mathrm{X})$ : curve connecting the SMPRT determined market clearing bids given as dots for the respective supply of PCU slots.

The SMPRT algorithm determines the clearing price as the $\mathrm{X}^{*}$ th highest bid for the fixed $X^{*}$ supply of PCU slots which is less than the current demand of $X^{0}$. The clearing price (the curve with dots in Figure 8) needs to be read off from the appropriate market demand/aggregate bid curve. Thus, the market clearing price of $£ 2.90$ at the "cap” of 11,720 PCU is indicated by the vertical cursor in Panel C. The curve connecting the market clearing price at the different chosen levels of fixed supply of travel slots given in Panel $\mathrm{C}$ is the inverse equilibrium market demand function $\mathrm{P}(\mathrm{X})$ defined in equation (12) of Section 2.4. Note R-cap of 1.43 referred to in Figure 8 represents the relative excess demand of 5020 and is given by ratio of the current demand and the optimal physical “cap” of 11, 720.

\subsection{SMPRT prices, demand and value of time}

The SMPRT algorithm is designed so that the uniform application of the market clearing price $\mathrm{P}(\mathrm{X})$ to all bidders will reduce excess demand from $\mathrm{X}^{0}$ to $\mathrm{X}$. Thus, starting at zero clearing price at current demand, as supply of travel slots are reduced, the price increases along the inverse equilibrium demand function $\mathrm{P}\left(\mathrm{X}^{*}\right)$ till the price of $£ 2.90$ at the "cap” of 11,720 is obtained. At this point, AKT/hr has increased to $18.85 \mathrm{kms}$ from $4.11 \mathrm{kms}$. These SMPRT prices are reported in Table 6 along with the demand elasticities, $\varepsilon_{X / P}$, the speed elasticities, $\varepsilon_{S / X}$, with the former defined in a similar way as in (3). These are evaluated at points $\mathrm{X}^{\#}<\mathrm{X}<\mathrm{X}^{0}$ with demand and prices modelled as changing incrementally. Thus, $\varepsilon_{X / P}=0.71$ will be taken to be the demand elasticity at the cap $X^{\#}=11718$ when demand is reduced from 12555 . If demand is reduced to points $\mathrm{X}$ from $\mathrm{X}^{0}$ at zero price, the relevant data is given in 
brackets in Table 6. As seen in Table 6, the demand elasticities, $\varepsilon_{X / P}$, are inelastic and less than one in the relevant range of demand and the elasticity ranges from 0.11 to 0.71 at the cap volume $X^{\#}=11718$.

Table 6 Prices and elasticities of SMPRT model for different PCU volumes. (Note: $\varepsilon_{X / P}$ takes negative values.)

\begin{tabular}{|c|c|c|c|c|c|c|c|}
\hline $\begin{array}{c}\text { PCU } \\
X\end{array}$ & AKT(X) & $\begin{array}{c}\text { Clearing } \\
\text { price } \\
\text { SMPRT } \\
\text { model }\end{array}$ & $\begin{array}{c}\text { Change in } \\
\text { demand } \\
\Delta \mathrm{X} \%\end{array}$ & $\begin{array}{c}\text { Change } \\
\text { in price } \\
\Delta \mathrm{P} \%\end{array}$ & $\begin{array}{c}\text { Change } \\
\text { in } \\
\text { AKT(X) } \\
\Delta \mathrm{AKT} \%\end{array}$ & $\begin{array}{c}\text { Elasticity } \\
\text { of AKT to } \\
\text { PCU } \\
\varepsilon_{S / X}\end{array}$ & $\begin{array}{c}\text { Elasticity } \\
\text { of } \\
\text { demand } \\
\text { to price } \\
\varepsilon_{X / P}\end{array}$ \\
\hline 11718 & 18.85 & $£ 2.90$ & $\begin{array}{c}0.071 \\
(0.43)\end{array}$ & $\begin{array}{c}0.10 \\
(1.00)\end{array}$ & $\begin{array}{c}0.128 \\
(0.78)\end{array}$ & $\begin{array}{c}1.81 \\
(1.82)\end{array}$ & $\begin{array}{c}0.71 \\
(0.43)\end{array}$ \\
\hline 12555 & 16.42 & $£ 2.61$ & $\begin{array}{c}0.06 \\
(0.34)\end{array}$ & $\begin{array}{c}0.11 \\
(1.00)\end{array}$ & $\begin{array}{c}0.148 \\
(0.75)\end{array}$ & $\begin{array}{c}2.40 \\
(2.21)\end{array}$ & $\begin{array}{c}0.57 \\
(0.34)\end{array}$ \\
\hline 13392 & 13.99 & $£ 2.32$ & $\begin{array}{c}0.13 \\
(0.25)\end{array}$ & $\begin{array}{c}0.34 \\
(1.00)\end{array}$ & $\begin{array}{c}0.71 \\
(0.71)\end{array}$ & $\begin{array}{c}2.99 \\
(2.82)\end{array}$ & $\begin{array}{c}0.36 \\
(0.25)\end{array}$ \\
\hline 15066 & 8.76 & $£ 1.52$ & $\begin{array}{c}0.11 \\
(0.11)\end{array}$ & $\begin{array}{c}1.00 \\
(1.00)\end{array}$ & $\begin{array}{c}0.53 \\
(0.53)\end{array}$ & $\begin{array}{c}4.77 \\
(4.77)\end{array}$ & $\begin{array}{c}0.11 \\
(0.11)\end{array}$ \\
\hline 16740 & 4.11 & $£ 0.00$ & - & - & - & - & - \\
\hline
\end{tabular}

Table 7 reports the pro rata daily and hourly income of the different marginal bidders who clear the market at the respective PCU volumes. This then determines the value of time, VOT, for these marginal drivers as travel time increases with a reduction in speed caused by congestion. This is to be compared with $\overline{V O T}$, viz. the average value of time of the infra marginal driver with $\overline{y^{h}}$ defined in equation (16). Note $\overline{V O T}$ for all the infra marginal users is greater than, VOT, which applies to the marginal user.

Table 7 :Value of time (VOT) of marginal user, private unit cost of travel and $\overline{V O T}$, Average value of time of infra marginal users

\begin{tabular}{|c|c|c|c|c|c|c|}
\hline PCU & $\begin{array}{c}\mathrm{y}^{\mathrm{d}} \\
\text { Daily income of } \\
\text { marginal } \\
\text { user } \\
2 \\
2\end{array}$ & $\begin{array}{c}\mathrm{y}^{\mathrm{h}} \\
\text { Hourly income of } \\
\text { marginal user }\end{array}$ & $\begin{array}{c}\text { VOT } \\
y^{h / A K T(X) x} x \\
\text { Dist } \\
\\
4\end{array}$ & $\begin{array}{c}\overline{y^{d}} \\
\text { Average } \\
\text { daily } \\
\text { income } \\
\text { infra } \\
\text { marginal } \\
\text { user } \\
\\
5\end{array}$ & $\begin{array}{c}\overline{y^{h}} \\
\text { Average } \\
\text { hourly income } \\
\text { infra marginal } \\
\text { users } \\
\text { Eq (16) } \\
6\end{array}$ & $\begin{array}{c}\overline{\overline{V O T}} \\
\text { Average of } \\
\text { infra marginal } \\
\text { user } \\
\overline{y^{h}} / A K T(X) \\
x \text { Dist } \\
\text { Eq (16) } \\
7\end{array}$ \\
\hline 11718 & $£ 62.44$ & $£ 7.80$ & $£ 0.75$ & $£ 103.09$ & $£ 12.87$ & $£ 1.23$ \\
\hline 12555 & $£ 59.19$ & $£ 7.39$ & $£ 0.83$ & $£ 100.14$ & $£ 12.51$ & $£ 1.37$ \\
\hline 13392 & $£ 55.95$ & $£ 6.99$ & $£ 0.90$ & $£ 97.84$ & $£ 12.23$ & $£ 1.57$ \\
\hline 15066 & $£ 49.63$ & $£ 6.20$ & $£ 1.27$ & $£ 93.22$ & $£ 11.65$ & $£ 2.39$ \\
\hline 16740 & $£ 42.00$ & $£ 5.25$ & $£ 2.30$ & $£ 88.47$ & $£ 11.05$ & $£ 4.84$ \\
\hline
\end{tabular}


(Note : The * values are interpolated; VOC is $£ 0.47$; the pro rata hourly income is obtained by dividing the daily rate by 8 working hours).

In Table 8, we first note that the SMPRT willingness to pay approach for the given volume of traffic and speed yields the market clearing price as the marginal gross benefit net the private cost of travel of the marginal user. Thus, the SMPRT prices are obtained from the data in columns 3 and 4 of Table 8. The row that has been highlighted shows that social optimum volume of drivers, $X^{*}=12136$. Here the MSC $=$ MGB at approximately $£ 4.00$. As per equation (18), we have the SMPRT $P\left(X^{*}\right)$ is equal to the congestion externality cost of $£ 2.76$. At the cap, $X^{\#}=11,718$, we see that the price of $£ 2.90$ signals the willingness to pay by the marginal 11,718 highest net value commuters. At this cap level, the price of $£ 2.90$ is greater than the congestion externality cost of $£ 2.24$ given in column 7 of Table 8 . Indeed, there is scope for the inclusion of costs from environmental externalities of about $£ 0.66$ (ie. $£ 2.90$ - £2.24) and maintain demand at 11,718. Note, Figure 2 has been calibrated in terms of the data given in Table 8 . The power of the method lies in the fact that the inverse demand function in Figure 2 has been obtained from the equilibrium market clearing price function (the dotted curve) obtained from the SMPRT simulator shown in Figure 8.

Table 8

Social optimum and SMPRT Price compared to congestion charge with homogeneous VOT (GCF) and with heterogeneous VOT

\begin{tabular}{|c|c|c|c|c|c|c|}
\hline $\begin{array}{c}\text { PCU } \\
X\end{array}$ & $\begin{array}{c}\text { Clearing } \\
\text { price } \\
\text { SMPRT } \\
\text { model } \\
2\end{array}$ & $\begin{array}{c}\text { Marginal } \\
\text { social } \\
\text { gross } \\
\text { benefit } \\
\alpha y^{\mathrm{d}} \\
3\end{array}$ & $\begin{array}{c}\text { Private cost: } \\
\text { VOC+VOT } \\
\text { (VOT given in } \\
\text { Table } 7 \\
\text { column } 4 \text { plus } \\
\text { VOC= } £ 0.47 \text { ) } \\
4\end{array}$ & $\begin{array}{l}\text { Marginal } \\
\text { social cost } \\
\text { heterogeneous } \\
\text { case } \\
\text { MSC= } \\
\text { private cost + } \\
\text { E(X) } \\
\text { Eq. (15) } \\
5\end{array}$ & $\begin{array}{l}\text { Congestion } \\
\text { charge } \\
\text { generalized } \\
\text { cost function } \\
\text { approach } \\
\text { (GCF) } \\
\\
6\end{array}$ & $\begin{array}{c}\begin{array}{c}\text { Congestion } \\
\text { charge } \\
\text { heterogeneous } \\
\text { case }\end{array} \\
\mathrm{E}(\mathrm{X})=\overline{V O T} \\
E_{S / X} \\
\text { Eq. (16) } \\
7\end{array}$ \\
\hline 11718 & $£ 2.90$ & $£ 4.12$ & $£ 1.22$ & $£ 3.46$ & $£ 2.04$ & $£ 2.24$ \\
\hline $12136^{*}$ & $£ 2.76^{*}$ & $£ 4.00^{*}$ & $£ 1.26 *$ & $£ 4.02^{*}$ & $£ 2.67^{*}$ & $£ 2.76^{*}$ \\
\hline 12555 & $£ 2.61$ & $£ 3.91$ & $£ 1.30$ & $£ 4.58$ & $£ 3.30$ & $£ 3.28$ \\
\hline 13392 & $£ 2.32$ & $£ 3.69$ & $£ 1.37$ & $£ 6.06$ & $£ 4.56$ & $£ 4.69$ \\
\hline 15066 & $£ 1.52$ & $£ 3.28$ & $£ 1.75$ & $£ 13.15$ & $£ 11.62$ & $£ 11.40$ \\
\hline 16740 & $£ 0.00$ & $£ 2.77$ & $£ 2.77$ & $\begin{array}{l}- \\
-\end{array}$ & - & - \\
\hline
\end{tabular}

Note: The asterisk * denotes that this row has been interpolated.

Finally, we will compare the estimates for congestion externality cost using equations (15) and (16) in the heterogeneous VOT case and variants in the literature based on the generalized cost function (GCF) approach. We shall assume the homogeneous value of time VOT for road users in the North East is 2/3 of the VOT of 
$£ 17.76 / \mathrm{hr}$, recently used for London and the South East (Santos and Shaffer, 2005). Using equation (7) multiplied by the average trip length of $1.8 \mathrm{kms}$, this yields the figures given in column 6 in Table $8 .^{29}$ Absenting knowledge of price demand elasticities and the inverse demand function for the traffic system, which is not integral to the GCF approach, it is not clear which volume of $\mathrm{X}$ is the appropriate one at which the congestion charge will secure demand approximately consistent with the GCF charge. Given the demand elasticities estimated here, the GCF congestion charge will be a blunt instrument being either too high at $£ 3.30$ or too low at $£ 2.04$ to fine tune demand to either 11,718 or 12,555 . At the social optimum of $X^{*}=12136$, the GCF externality cost at $£ 2.67$ is about 10 pence less than the one calculated by the SMPRT model.

\subsection{Winners and losers across socio-economic groups from road user charging}

From the bid submission process and the winner determination algorithm of SMPRT, Panel (i) in Figure 9 below reports the percentage of total commuters that belong to the different socio-economic groups. The largest group of commuters belongs to the semi-routine group (36\%) followed by the managerial group (21\%), professionals (17\%), administrators (14\%), sales and routine at 7\% each and finally, personal services at $2 \%$. In Panels ii, iii and iv of Figure 13, the supply of slots has been reduced by $10 \%, 20 \%$ and $30 \%$, respectively, from existing demand. How the rise in the market clearing price affects the different socio-economic groups is given as the new percentage of commuters from each socio-economic group relative to the original demand. Thus, using Table 9, with a reduced supply of travel slots at 15,066, total numbers of commuters belonging to the semi-routine groups has fallen to 5,590 and this constitutes about $34 \%$ of the original number of road users. Thus, distributional impact of road pricing can be assessed in an integrated way using the bid based approach to road pricing.

Table 9

Absolute numbers of "winners" in socio-economic groups given prices at each PCU volume

\begin{tabular}{|l|l|l|l|l|}
\hline PCU & 11718 & 13392 & 15066 & 16740 \\
\hline Managers & 3050 & 3280 & 3380 & 3500 \\
\hline Professionals & 1950 & 2030 & 2120 & 2160 \\
\hline Semi-routine & 4430 & 5000 & 5590 & 5990 \\
\hline Administrative & 1060 & 1490 & 1920 & 2400 \\
\hline Personal service & 130 & 150 & 230 & 300 \\
\hline Sales & 530 & 750 & 980 & 1200 \\
\hline Routine & 560 & 680 & 840 & 1150 \\
\hline
\end{tabular}

\footnotetext{
${ }^{29}$ For example £2.04 at PCU volume of 11718 we have:

GCF Congestion Charge $\left(X^{\#}\right)=\frac{\frac{2}{3} £ 17.76}{A K T(X)} \varepsilon_{S \mid X}$ Dist $=\frac{£ 11.82}{18.85} 1.81 \times 1.8=£ 2.04$.
} 


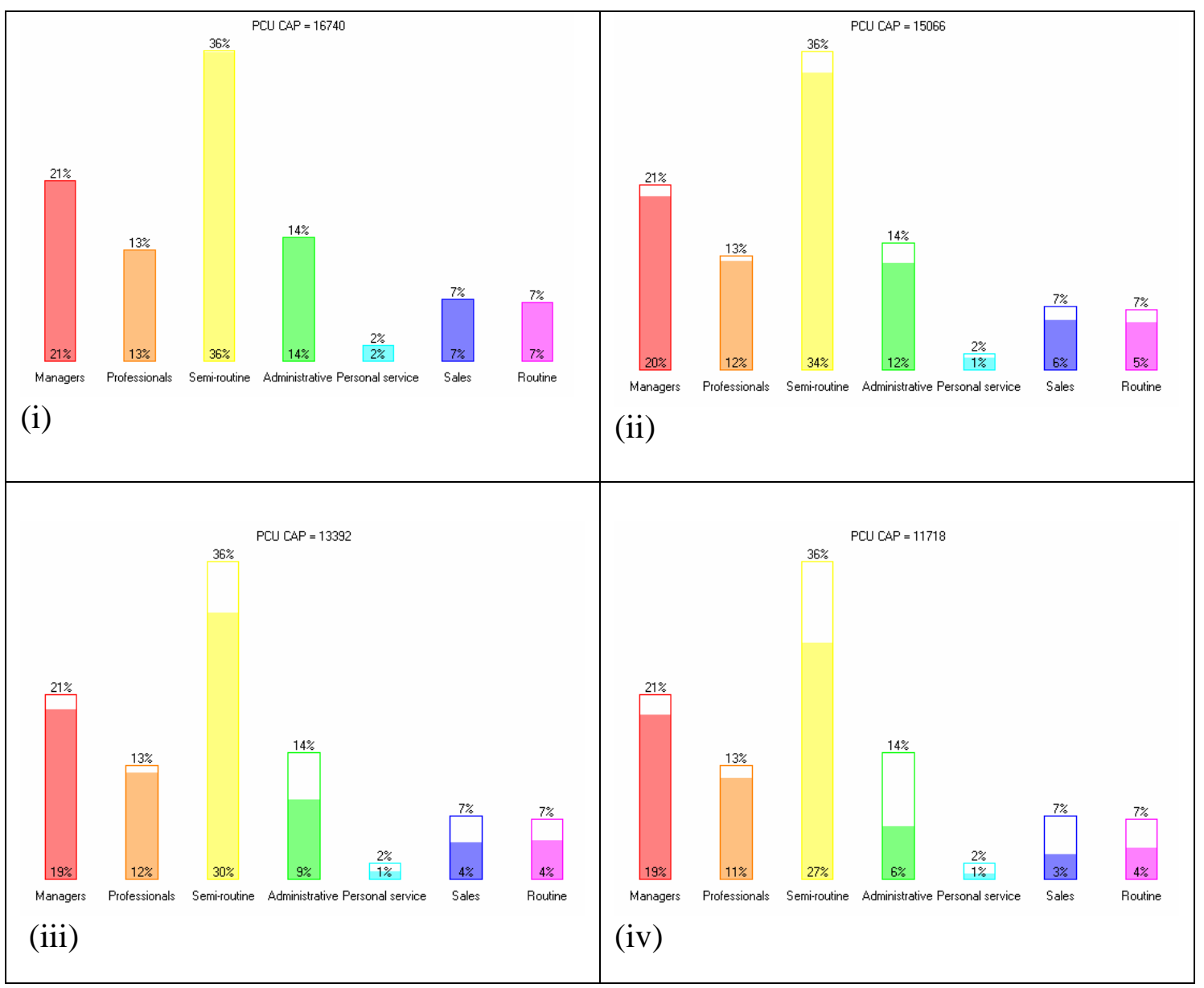

Figure 9: Winners and losers across socio-economic groups

\section{Concluding remarks and future work}

The SMPRT project has delivered an integrated, agent based methodology based on the "cap" and trade approach for the pricing and control of negative externalities to determine peak time congestion charging in a cordon area of a road network system. The demonstrated principles and steps in its implementation can be followed in any road transport congestion pricing problem where congestion hot-spots in the road system have been identified. The methodology for determining the "cap" in a cordon area of the road network, though computationally intensive and based on a micro-simulative transport model of fine granularity, is within the scope of state of the art transport micro simulators. The "cap” is the point at which the so called total output function of road travel, which is total distance travelled in the cordon area by all cars for the fixed time slice, falls with incremental increases in volumes of traffic. This is a point at which the traffic efficiency and social welfare gains from travel begin to diminish rapidly. The electronic Dutch auction heterogeneous bid submission process, based on the actual distribution of income and the socio-economic characteristics of road users who traverse the cordon area, has obvious advantages over extant generalized cost function methods for estimating congestion charging. These include the capacity to derive the inverse demand function for the traffic system and also better capabilities for probing the system for demand elasticities, especially for the different socio-economic classes. Further, our approach clearly indicates that an arbitrary increase in road user charging beyond the "cap" implied 
price only contributes to the coffers of the monopoly provider and cannot be justified in terms of gains in traffic efficiency. The transparency of the SMPRT algorithm should provide a bulwark against over-pricing.

The simulation of the willingness to pay, based on the pro rata daily income distribution across the heterogeneous groups of road users and which is calibrated to satisfy the revealed preference in the current situation of zero price and hence zero willingness to pay, provides an important source of data analysis of the value of travel time. This approach can be contrasted with the econometric based analysis of revealed preference of road users in the dynamic pricing on designated express lanes and of the stated preferences arising from hypothetical responses to questionnaires on road pricing (Small et. al. (2005), and Brownstone et. al. (2002)).

The SMPRT bid only pricing, like the London congestion charge, can be regressive. The SMPRT algorithm and its agent based approach can identify who is being priced out and can help in targeting better public transport or other welfare measures. In a double sided auction with fully tradable permits, those who sell the permits receive the incomes and hence, avoidance of road use is not only less regressive but also provides direct economic incentives to road users and to others indirectly to economize on road use and use the money to use other transport modalities. The design of a system of fully tradable road user permits, however, is more complex in terms of property rights allocations, and the full study of its socioeconomic consequences is beyond the scope of this project.

Finally, it is important to report the robustness tests for the efficacy of the proposed auction protocol in delivering the prices and revenues obtained under the assumption that agents bid true values. These tests have been done and it has been found that the large numbers of bidders with excess demands of $20 \%$ or more are sufficient for the marginal bids to reflect true value. A fuller discussion of this can found in Markose et. al. (2006).

\section{Appendix A}

Here we show the nature of the bid schedule if agents use a constant bid function in terms of their fixed gross budget $\alpha y^{d}\left(n_{i g}\right)$ rather than the net benefit rule in equations (10) and (11) where the increase in travel time costs are deducted. This implies inelastic bids given in Figure A1 and agents do not have a different bid for each PCU level and the corresponding speed, AKT. 


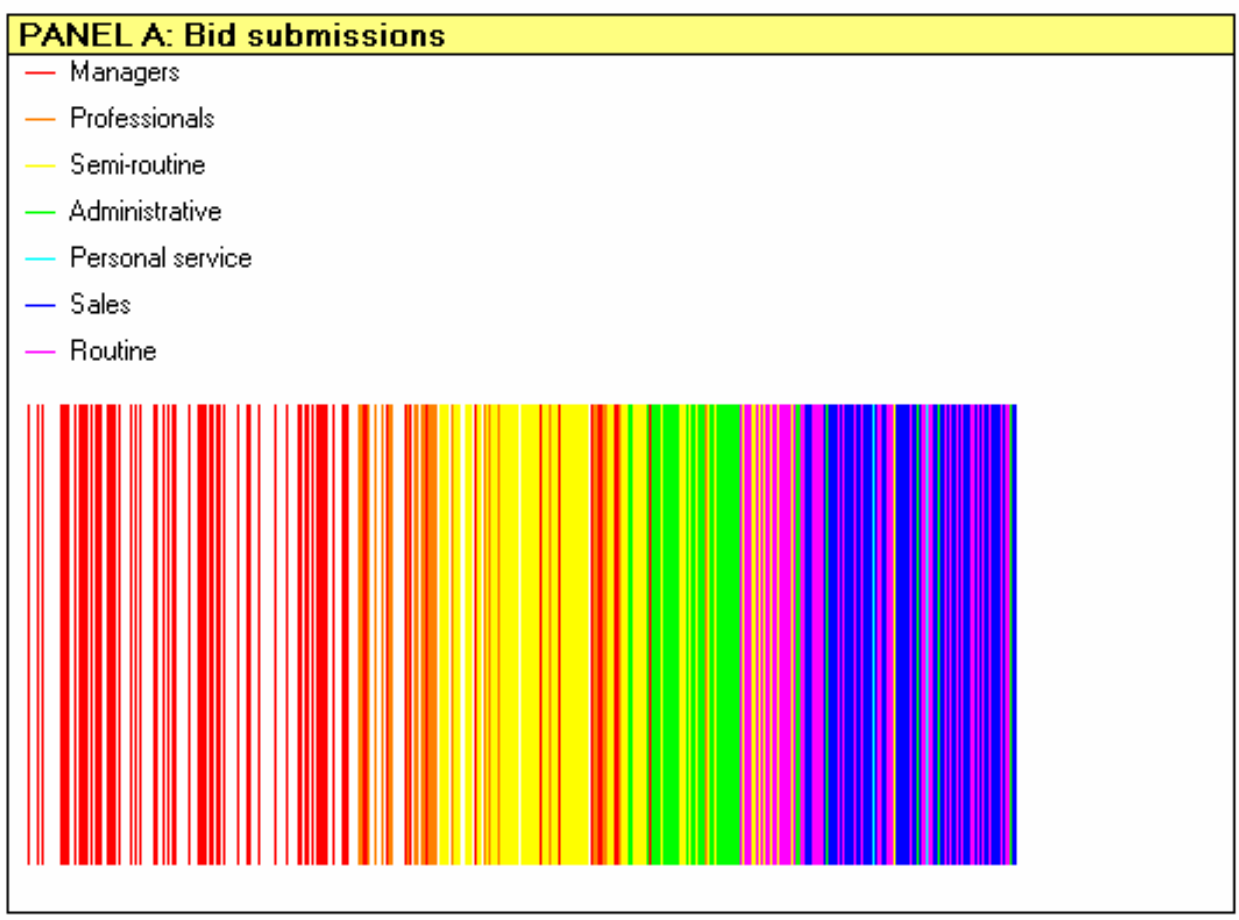

40

Figure A1: Constant bid functions based solely on a fixed budget $\alpha \mathrm{y}^{\mathrm{d}}\left(\mathrm{n}_{\mathrm{ig}}\right)$

The SMPRT algorithm that determines bids from highest to lowest obtains a single market demand function and the fixed supply determines the market clearing price at each $\mathrm{X}$ as shown below. For the same income distribution, the cap price at $\mathrm{X}=11,720$ is $£ 4.07$ as compared to $£ 2.90$ in the case of a congestion sensitive bid function.

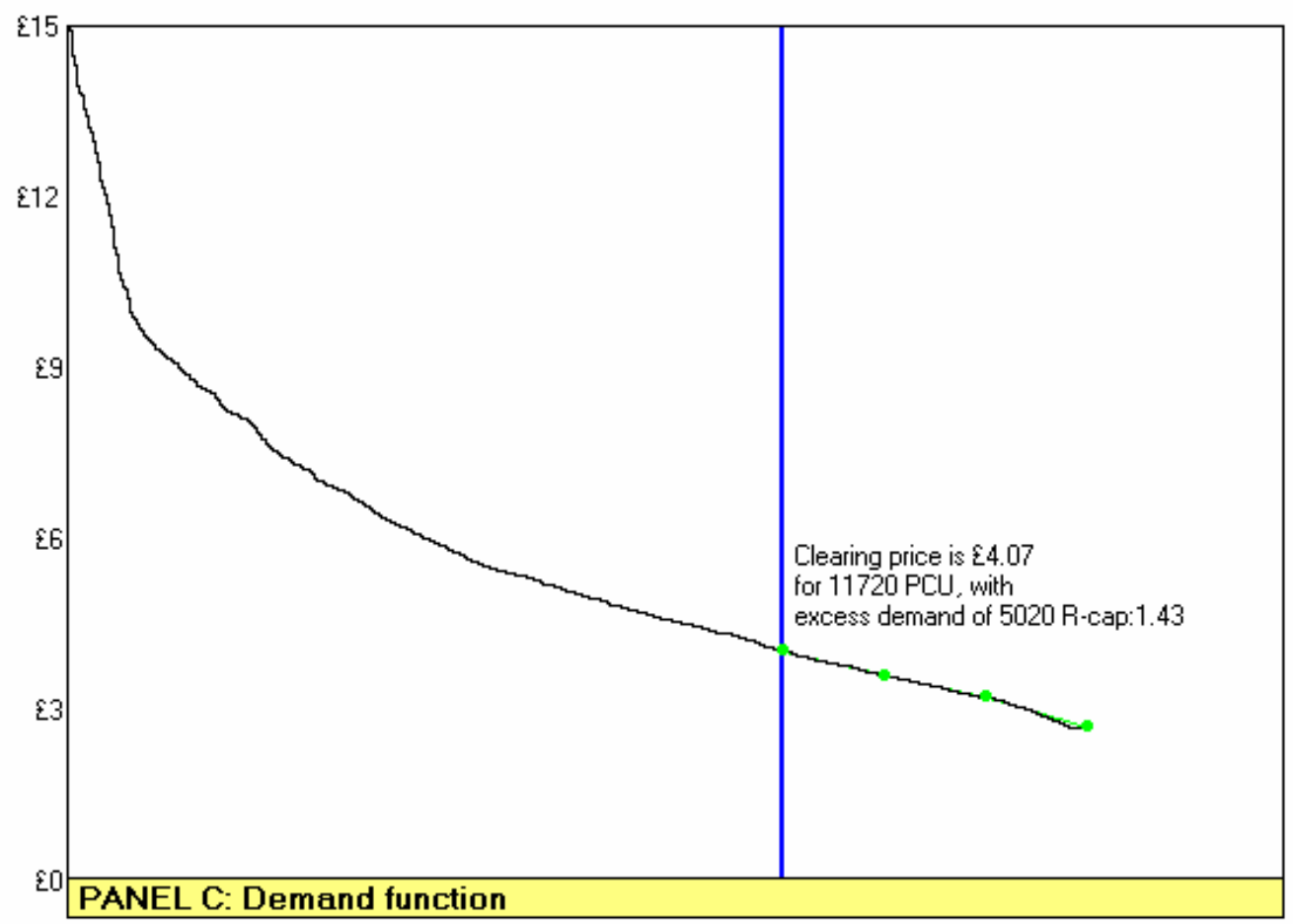




\section{References}

Allen, P.M., 1997a. Cities and Regions as Self-Organising Systems: Models of Complexity. Taylor and Francis, London.

Allen, P.M., 1997b. Cities and regions as evolutionary complex systems. Geographical Systems 4, 103-130.

Andreoni, J., Miller, J.J., 1995. Auctions with artificial adaptive agents. Games and Economic Behaviour 10, 39-64.

Bower, J., Bunn, D., 2001. Experimental analysis of the efficiency of uniform-price versus discriminatory auctions in the England and Wales electricity market. Journal of Economic Dynamics and Control, 25, 561-592.

Blythe, P.T., 1993. A Description of ADEPT Demonstration of Congestion Management Equipment in the City of Cambridge. Commission of European Communities.

Brownstone, D. Ghosh, A., Golob, T., Kazimi, C., and Amelsfort D. van, 2002, Drivers' Willingness-to-pay to reduce travel time: evidence from the San Diego I-15 congestion pricing project, Transportation Research, A, 37(2), 373-387.

Bunn, D.W., Oliveira, F.S., 2001. Agent-based simulations : an application to the new electricity trading arrangements of England and Wales. IEEE Transactions on Evolutionary Computation, special issue: Agent Based Computational Economics, 5(5), 493-503.

Dash, R., Jennings, N.R, Parkes, D.C., 2003. Computational mechanism design: a call to arms. IEEE Intelligent System, November/December, 40-47.

Erev, I., Roth, A., 1998. Predicting how people play games: reinforcement learning in experimental games with unique, mixed strategy equilibria. American Economic Review 88, 848-881.

Friedman, D. , Sunder, S., 1994. Experimental Methods: A Primer for Economists. Cambridge University Press, Cambridge.

Goodwin, P., 1992. A review of new demand elasticities with reference to short and long run effects to price changes. Journal of Transport Economics and Policy 26, 155159.

Goodwin, P., Dargay, J., Hanly, M., 2004. Elasticities of road traffic and fuel consumption with respect to price and income: a review. Transport Reviews 24, 275292.

Hardin, G., 1968. The tragedy of the commons. Science 162, 1243-1248. 
Joskow, P., Schmalensee, R., Bailey, E., 1998. The market for sulphur dioxide emission, American Economic Review, 88, 669-685.

Koesrindartoto, D., 2004. Treasury auction, uniform or discriminatory ? An agentbased approach, Economics Working Paper No. 04013, Department of Economics, Iowa State University.

Koesrindartoto, D., Tesfatsion, L., 2004. Testing the reliability of FERC's wholesale power market platform: an agent-based computational economics approach.

Proceedings of the $24^{\text {th }}$ USAEE/IAEE North American Conference, Washington, D.C., U.S.A.

Oum T., 1999. Concepts of price elasticities of transport demand. Journal of Transport Economics and Policy 26, 139-154.

Ledyard, J., Szakaly-Moore, K., 2004. Designing organizations for trading pollution rights. mimeo, California Institute of Technology, Pasadena.

Mackie-Mason, J.K , Varian H.R, 1995. Pricing congestible network resources. IEEE Journal of Selected Areas in Communications 13,1141- 1149.

Markose, S.M., Sunder, S., 2007 (forthcoming). Humans, Automatons and Markets: Computational Micro-Structure Design, Cambridge University Press, Cambridge.

Markose, S.M, Alentorn ,A., Koesrindartoto, Blythe, P., Ehlert, A., Grosso, S., Allen, P. (2006), Intelligent charging, Smart Market Protocols for Road Transport (SMPRT), Final Report for IIS Foresight Project.

http://www.foresight.gov.uk/Previous_Projects/Intelligent_Infrastructure_Systems/In $\underline{\text { dex.htm }}$

Markose, S.M, Alentorn ,A., Koesrindartoto, D.,2006. Robustness of the SMPRT auction design for road user pricing. Mimeo,CCFEA, University of Essex, Colchester.

McCabe, K., Rassenti, S., Smith, V., 1991. Smart computer-assisted markets. Science 254, 534-538.

National Statistics, Census 2001. Origin-Destination Statistics, local authorities, U.K.

Nash, C.A, and Sansom, T., 2001. Pricing European Transport Systems: Recent Developments and Evidence from Case Studies. Journal of Transport Economics 35, $3,363-380$.

Ove Arup \& Partners International Limited and Scott Wilson Scotland Ltd in association with Marcial Echenique \& Partners, Social Research Associates Ltd, November, 2002. Tyneside Area Multi-Modal Study: Study Report..

Pigou, A C., 1920. Wealth and Welfare. Macmillan, London.

Roth, E.A., 2002. The economist as engineer: game theory, experimentation, and computation as tools for design economics. Econometrica 70, 1341-1378. 
Schmalensee, R., Joskow, P., Ellerman D., Montero J., Bailey, E., 1998. An interim evaluation of sulfur dioxide emissions trading. Journal of Economic Perspectives 12, 53-68.

Shaffer, B., Santos, G., 2005. Preliminary results of the London congestion charging scheme. working paper no. 04-3979, Department of Applied Economics, University of Cambridge, Cambridge.

Small, K.A., Winston, C., and Yan, J., 2005, Uncovering the distribution of motorists' preferences for travel time and reliability, Econometrica, vol. 73, 4, 1367-1382.

Transport for London, 2003. Central London Congestion Charging Scheme: Three Months On. Greater London Authority, London.

Varian, H., 1993. Intermediate Microeconomics, $3^{\text {rd }}$ edition. Norton international student edition.

Vickrey, W., 1955. Pricing in transportation and public utilities: some implications of marginal cost pricing for public utilities. The American Economic Review, supplement, Papers and Proceedings, 605-620.

Vickery, W., 1969. Congestion theory and transport investment. The American Economic Review Proceedings 59, 251-260.

Walters, A., 1961. The theory and measurement of private and social cost of highway congestion. Econometrica 29, 676-699. 